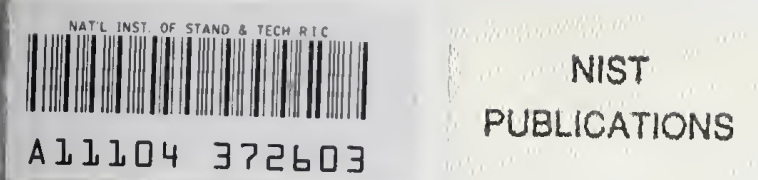

NISTIR 5304

\title{
THE USE OF COMPUTER MODELS TO PREDICT TEMPERATURE AND SMOKE MOVEMENT IN HIGH BAY SPACES
}

Kathy A. Notarianni and William D. Davis

Building and Fire Research Laboratory

Prepared for:

MNS

National Aeronautics and Space Administration Goddard Space Flight Center

Greenbelt, MD 20771

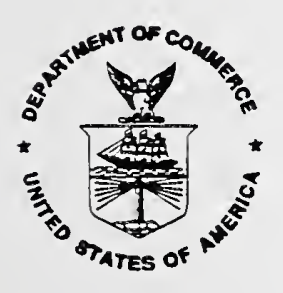

U.S. Department of Commerce

Technology Administration

National Institute of Standards and Technology

Gaithersburg, MD 20899

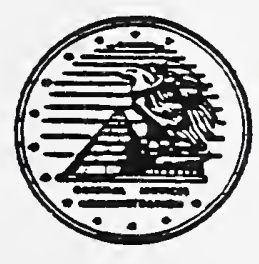

General Services Administration

Public Building Service

Office of Real Property Management and Safety

Washington, DC 20405 



\section{THE USE OF COMPUTER MODELS TO PREDICT TEMPERATURE AND SMOKE MOVEMENT IN HIGH BAY SPACES}

Kathy A. Notarianni and William D. Davis

December, 1993

Building and Fire Research Laboratory

Gaithersburg, Maryland 20899

\section{U.S. Department of Commerce}

Ronald H. Brown, Secretary

Technology Administration

Mary L. Good, Under Secretary for Technology

National Institute of Standards and Technology

Arati Prabhakar, Director
Prepared for:

National Aeronautics and Space Administration John M. Klineberg, Director Goddard Space Flight Center Greenbelt, MD 20771

Frederick D. Gregory, Associate Administrator Office of Safety and Mission Assurance Washington, D.C. 20546

General Services Administration Roger W. Johnson, Administrator Public Buildings Service Kenneth R.Kimbrough, Commissioner Office of Real Property Management and Safety Washington, D.C. 20405 
. 


\section{CONTENTS}

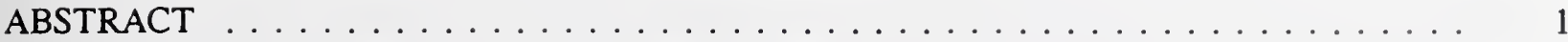

SECTION A: COMPARISON OF COMPUTER MODEL PREDICTIONS TO TEMPERATURE MEASUREMENTS FROM A HIGH BAY FIRE EXPERIMENT . . . . . . . . . . . . . . . 3

SECTION B: MODELING OF THE HOT GAS MOVEMENT IN A NASA HIGH BAY CLEAN ROOM USING A COMPUTATIONAL FLUID DYNAMICS MODEL . . . . . . . . . . . 47

ACKNOWLEDGEMENTS $\ldots \ldots \ldots \ldots \ldots \ldots \ldots \ldots \ldots \ldots \ldots \ldots \ldots$ 



\section{ABSTRACT}

The Building and Fire Research Laboratory (BFRL) was given the opportunity to make measurements during fire calibration tests of the heat detection system in an aircraft hangar with a nominal $30.4 \mathrm{~m}$ (100 ft) ceiling height near Dallas, TX. Fire gas temperatures resulting from an approximately $8250 \mathrm{~kW}$ isopropyl alcohol pool fire were measured above the fire and along the ceiling. The results of the experiments were then compared to predictions from the computer fire models DETACT-QS, FPETOOL and LAVENT. In section A of the analysis conducted, DETACT-QS and FPETOOL significantly underpredicted the gas temperatures. LAVENT at the position below the ceiling corresponding to maximum temperature and velocity provided better agreement with the data. For large spaces, hot gas transport time and an improved fire plume dynamics model should be incorporated into the computer fire model activation routines. A computational fluid dynamics (CFD) model, HARWELL FLOW3D, was then used to model the hot gas movement in the space.

Reasonable agreement was found between the temperatures predicted from the CFD calculations and the temperatures measured in the aircraft hangar. In section B, an existing NASA high bay space was modelled using the computational fluid dynamics model. The NASA space was a clean room, $27.4 \mathrm{~m}$ ( $90 \mathrm{ft}$ ) high with forced horizontal laminar flow. The purpose of this analysis is to determine how the existing fire detection devices would respond to various size fires in the space. The analysis was conducted for $32 \mathrm{MW}, 400 \mathrm{~kW}$, and $40 \mathrm{~kW}$ fires.

Key words: clean rooms; computer models; computational fluid dynamics; detector response; field modeling; fire detection; fire models; forced air flow; fire plumes; fire tests; high bays; response time; sprinkler response 



\section{THE USE OF COMPUTER MODELS TO PREDICT TEMPERATURE AND SMOKE MOVEMENT IN HIGH BAY SPACES}

SECTION A: COMPARISON OF COMPUTER MODEL PREDICTIONS TO TEMPERATURE MEASUREMENTS FROM A HIGH BAY FIRE EXPERIMENT

Kathy A. Notarianni and William D. Davis

\section{SECTION CONTENTS}

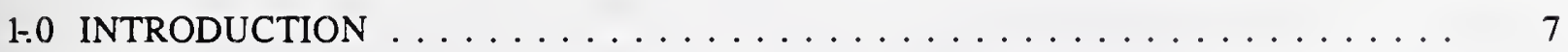

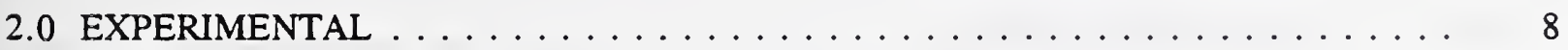

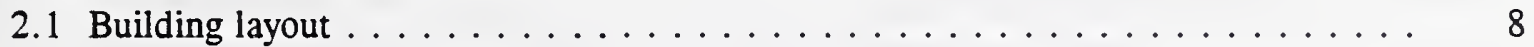

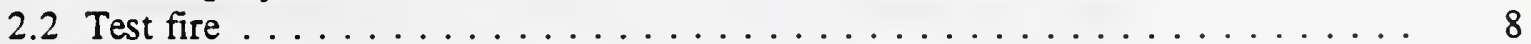

2.3 Measurements . . . . . . . . . . . . . . . . . 10

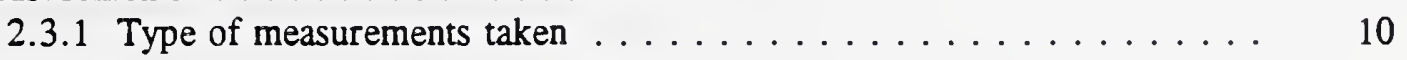

2.3.2 Uncertainty of measurements . . . . . . . . . . . . . 10

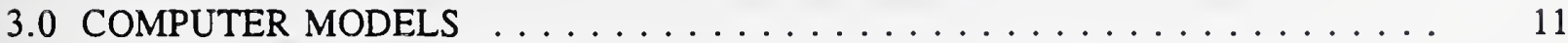

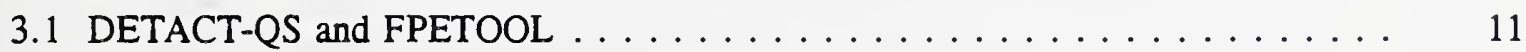

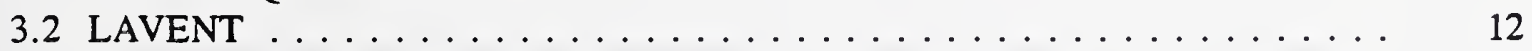

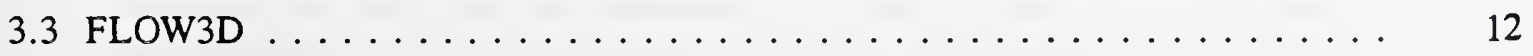

4.0 COMPARISON OF COMPUTER FIRE MODELS TO MEASUREMENTS $\ldots \ldots \ldots 13$

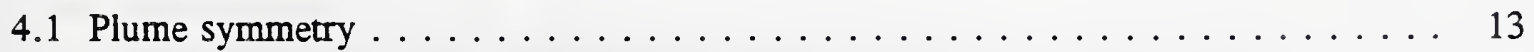

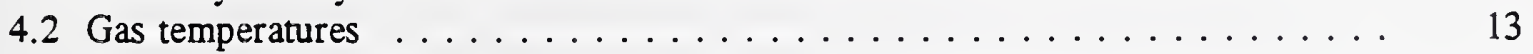

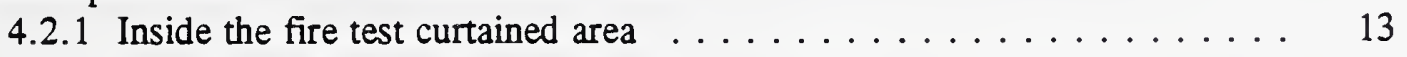

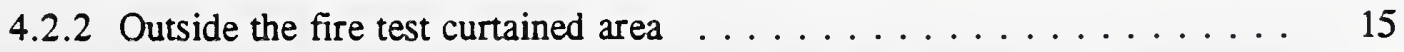

4.2 .3 Sensitivity to heat release rate $\ldots \ldots \ldots \ldots \ldots \ldots \ldots \ldots \ldots$

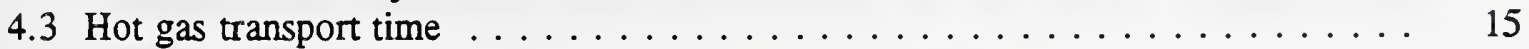

5.0 COMPARISON OF FIELD MODEL (CFD) CALCULATIONS TO

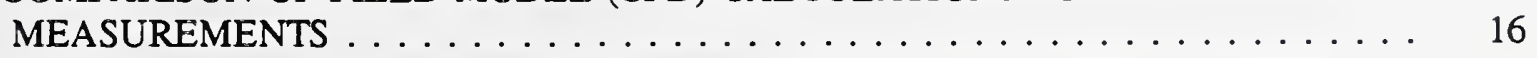

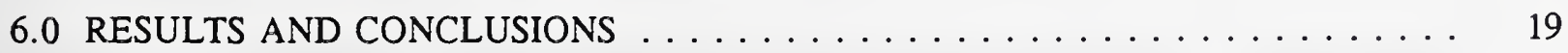

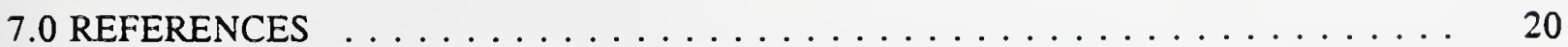




\section{LIST OF TABLES}

Table 1.

Heat release rate as a function of time

Table 2.

DETACT-QS input values

Table 3.

FPETOOL input values

Table 4.

LAVENT input values

Table 5.

Numerical Trials . 25

Table 6.

FLOW3D inputs

Table 7.

Plume symmetry .

Table 8.

Mean gas temperatures

Table 9.

Hot gas transport time 


\section{LIST OF FIGURES}

Figure $1 . \quad$ Picture of hangar $\ldots \ldots \ldots \ldots \ldots \ldots \ldots \ldots \ldots \ldots . \ldots \ldots$

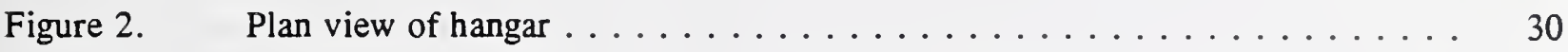

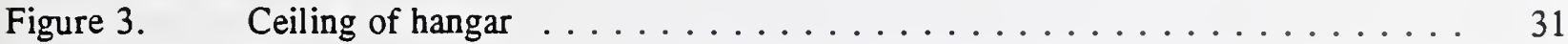

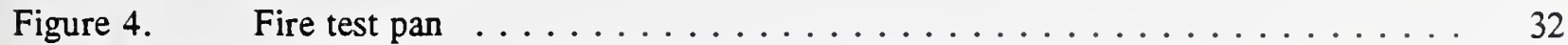

Figure $5 . \quad$ Picture of fire at steady state $\ldots \ldots \ldots \ldots \ldots \ldots \ldots \ldots \ldots \ldots \ldots$

Figure $6 . \quad$ Instrumentation layout $\ldots \ldots \ldots \ldots \ldots \ldots \ldots \ldots \ldots \ldots \ldots \ldots$

Figure 7. Measured vs. predicted gas temperatures at a radial distance of $1.5 \mathrm{~m}$ from the fire centerline, $r / h=0.05 . d=$ distance below the ceiling $\ldots \ldots \ldots 35$

Figure 8. Measured vs. predicted gas temperatures at a radial distance of $6.1 \mathrm{~m}$ from the fire centerline, $r / h=0.20 . d=$ distance below the ceiling . . . . . 36

Figure 9. Illustration of plume and ceiling jet regions of a typical fire $\ldots \ldots \ldots \ldots \ldots$

Figure 10. Temperature distribution within the plume measured at radial distances $(r)$ of $0,1.5,3.0,4.6$, and $6.1 \mathrm{~m}$ from the fire centerline, $0.15 \mathrm{~m}$ below the

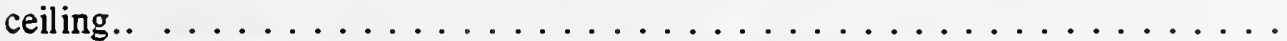

Figure 11. Measured vs. predicted gas temperatures at a radial distance of $6.1 \mathrm{~m}$ from fire centerline. Temperatures predicted using a 20 percent higher heat release rate of $9900 \mathrm{~kW}$.

Figure 12. Temperature at $4.6 \mathrm{~m}$ radial distance from fire centerline with time shift, $\mathrm{r} / \mathrm{h}=0.15 \mathrm{~d}=$ distance below the ceiling $\ldots \ldots \ldots \ldots \ldots \ldots \ldots$

Figure 13. Two dimensional section of a three dimensional grid used for the CFD calculations representing a portion of the fire test curtained area and the east adjacent curtained

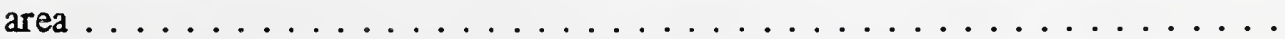

Figure 14. Comparison of CFD calculations using four different sets of $k-\epsilon$ constants to the measured plume centerline temperatures $\ldots \ldots \ldots \ldots \ldots \ldots \ldots$

Figure 15. Comparison of the Heskestad and McCaffrey plume correlations to the measured plume centerline temperatures

Figure 16. Comparison of calculations using four different sets of $k-\epsilon$ constants to the plume correlation of McCaffrey 
Figure 17. Comparison of a CFD calculation using the turbulence constants of $k 36$ and a more detailed grid with the measured plume centerline temperatures $\ldots \ldots \ldots$

Figure 18. Comparison of the CFD calculated ceiling temperatures using a detailed grid and the k36 turbulence constants to the measured temperatures at various radial distances from the fire centerline and $0.15 \mathrm{~m}$ below the ceiling. 


\subsection{INTRODUCTION}

Large spaces, such as those found in warehouses, historical buildings, atriums, and aircraft hangars, represent some of the most difficult fire protection challenges since they are frequently of historical significance, contain large quantities of fuel, have unique geometries, and/or present special life safety problems. Accurate detector activation predictions are important in these large spaces, as timely detection of a fire is more difficult due to the distance heat and products of combustion must travel to reach sprinklers and detectors. Since fires frequently grow at an exponential rate, an increased time to detection results in larger fires at the time of detection and larger fires to be suppressed by, e.g., an automatic sprinkler system. Even a modest uncertainty in the prediction of the activation time may lead to a large uncertainty in the fire size used to predict the hazard, a central element of many fire protection analyses.

There has been substantial effort to verify activation predictions in small and medium sized rooms, but little in large spaces. In January, 1993, a report describing model verification tests conducted in a $14 \mathrm{~m}$ (46 ft) high hangar was released by NIST [1]. Although the correlations in the computer fire models were based on ceiling heights up to $16 \mathrm{~m}(52 \mathrm{ft})$, previous to this study, comparisons of computer fire model predictions with experimental measurements for ceiling heights approaching that height had not been made. Conducting verification experiments for large spaces is difficult due to the lack of availability of adequate facilities for live fire tests. The largest dedicated fire test facility in the United States is limited to a height of $18.2 \mathrm{~m}(60 \mathrm{ft})$.

Why is model verification important? It is the responsibility of the user of a model to determine the suitability of a particular fire model for a given situation. A successful comparison of the model predictions with real-scale fire results helps the user make that decision. Comparison of a fire model against appropriately chosen experiments can provide the necessary base to extend the use of the model to real fire applications. Comparisons also allow model developers to examine the accuracy of a model and identify the needs for future model development. It is critical that the user have comparisons of model predictions to a wide range of experimental data.

The Building and Fire Research Laboratory (BFRL) was given the opportunity to make measurements during fire calibration tests of the heat detection system in an aircraft hangar with a nominal $30.4 \mathrm{~m}$ (100 ft) ceiling height near Dallas, TX. Three closed-door tests were conducted.

This project was funded in two phases. The U.S. General Services Administration (GSA) provided initial funding to conduct the experiments and to compare measured data with the predictions of DETACT-QS, LAVENT, and FPETOOL computer fire models. GSA's interest is to verify and provide recommendations for the use of the GSA Engineering Fire Assessment System for predicting the response of sprinklers and detectors in large spaces. FPETOOL is the main component of this system. The National Aeronautics and Space Administration (NASA) provided funding to compare the predictions of a computational fluid dynamics, or field model to the experiment. Comparisons of the experimental data to both the computer fire models and the field model are described in section A of this report. NASA also funded section B of this project which uses the field model to predict smoke movement in a NASA Goddard high bay space. NASA's interest is in the ability of field modelling to provide information that would be useful in selecting effective fire protection options for their high bay spaces. 


\subsection{EXPERIMENTAL}

\subsection{Building layout}

The aircraft hangar, pictured in figure 1, measured approximately $389 \mathrm{~m}$ (1280 ft) long by $115 \mathrm{~m}$ $(377 \mathrm{ft})$ deep $(81 \mathrm{~m}(270 \mathrm{ft})$ to a firewall), and $30.4 \mathrm{~m}(100 \mathrm{ft})$ high. The hangar had seven bays and was capable of housing seven wide-bodied aircraft side by side. The hangar contained draft curtains which were spaced approximately $12.5 \mathrm{~m}(41 \mathrm{ft})$ apart as shown in figure 2. Draft curtains are partitions extending vertically down from and perpendicular to the ceiling. Draft curtains are designed to slow the spread of combustion gases across the ceiling. The hot gases collect between the draft curtains and flow downward until spilling into the adjacent curtained areas. This concentration of smoke and hot gases inside the draft curtain is intended to speed up the operation of sprinklers within the curtained area. Draft curtains in this facility were $3.7 \mathrm{~m}(12 \mathrm{ft})$ deep. A plan view of the fire test curtained area and the two adjacent curtained areas is shown in figure 2.

The ceiling geometry is shown in figure 3. Perpendicular to the draft curtains, a series of large Ibeams are located near the ceiling which, when coupled with the draft curtain geometry, appear to partition the curtained areas into cubes. A second set of I-beams runs both below the draft curtains and the I-beams forming a second set of open cubes at a height of $24 \mathrm{~m}(79 \mathrm{ft}$ ) off the floor. Large Ibeams join the top and bottom I-beams in a triangular structure. The underside of the roof is made of corrugated steel with $38 \mathrm{~mm}$ ( $1.5 \mathrm{in})$ deep corrugations.

The front of the hangar consisted primarily of sliding doors, which if all were open would provide a maximum opening $289 \mathrm{~m}$ (948 ft) in length and $22 \mathrm{~m} \mathrm{(72} \mathrm{ft)} \mathrm{high.} \mathrm{The} \mathrm{hangar} \mathrm{also} \mathrm{contained} \mathrm{many}$ personnel doors both to the outside and to other parts of the building. The large doors were closed during the tests; however, some of these personnel doors may well have been open during the tests. (There was much work going on in the building during testing.) The building HVAC system was off for the duration of the three tests.

\subsection{Test fire}

The test fire was an array of nine pans, each $0.91 \mathrm{~m} \times 0.91 \mathrm{~m}(3 \mathrm{ft} \times 3 \mathrm{ft}$ ), placed together to form a square fire area totalling $7.5 \mathrm{~m}^{2}\left(81 \mathrm{ft}^{2}\right)$ as shown in figure 4 . The effective circular diameter of this fire is $3.1 \mathrm{~m}(10 \mathrm{ft})$. The pans were $0.076 \mathrm{~m}(0.25 \mathrm{ft})$ deep. The pans were supported on bricks, $127 \mathrm{~mm}(0.42 \mathrm{ft})$ off the floor. The test fuel was technical grade isopropyl alcohol. A total of 135 liters $(35.1 \mathrm{gal})$ of fuel was used per test, 15 liters $(4.0 \mathrm{gal})$ of fuel per pan. The fuel depth in each pan was approximately $13 \mathrm{~mm}(0.5 \mathrm{in})$. Cloth wicks were draped between the pans to aid in fire spread after ignition of one pan.

The fire was located on the floor in the center of the hangar building. At 8 seconds after ignition of the first pan, all the fuel pans were fully involved. A picture of the fire at steady-state is shown in figure 5. Steady burning was maintained for approximately three and one-half minutes, after which the flame height started to decrease. The fire was allowed to burn out, which took several additional minutes.

As there was no load cell or oxygen calorimeter available for use during these experiments, the heat release rate of the fire was estimated from previous burn tests conducted at NIST. These tests are described in [1]. Isopropyl alcohol pan fires $3.3 \mathrm{~m}^{2}\left(36 \mathrm{ft}^{2}\right)$ were conducted under the NIST large 
calorimeter. These tests used $4-0.91 \times 0.91 \mathrm{~m}(3 \times 3 \mathrm{ft})$ steel pans. The effective circular diameter of this fire was $2.1 \mathrm{~m}(6.9 \mathrm{ft})$. In the burn tests conducted, the average burning rate was 0.036 $\mathrm{kg} / \mathrm{m}^{2} / \mathrm{s}\left(0.0074 \mathrm{lb} / \mathrm{ft}^{2} / \mathrm{s}\right)$, and the average heat release rate was $3650 \mathrm{~kW}(3460 \mathrm{Btu} / \mathrm{s})$. The net heat of combustion is reported in the NFPA handbook [2] as $30.45 \mathrm{MJ} / \mathrm{kg}(13107 \mathrm{Btu} / \mathrm{lb})$.

Assuming there is sufficient oxygen available for complete combustion, the heat release rate of a fire can be calculated as:

$\dot{\mathrm{Q}}=\dot{\mathrm{m}}^{*} * \Delta \mathrm{h}_{\mathrm{c}} * \mathrm{~A}_{\mathrm{f}}$

where:

$\dot{\mathrm{Q}}=$ heat release rate $(\mathrm{kW})$

$\dot{\mathrm{m}} "$ = burning rate $\left(\mathrm{kg} / \mathrm{m}^{2} / \mathrm{s}\right)$

$\Delta \mathrm{h}_{\mathrm{c}}=$ net heat of combustion $(\mathrm{kJ} / \mathrm{kg})$

$A_{f}=$ surface area of fuel $\left(\mathrm{m}^{2}\right)$

To characterize the burning rate of a liquid pool fire, it is required that a classification be made according to the dominant heat transfer mechanism, which can be dependent on pool diameter [3]. When the pool diameter, $D$, is very small, $D<0.03 \mathrm{~m}(0.01 \mathrm{ft})$, conductive heat transfer determines the rate of burning, while the radiative term predominates if $\mathrm{D}$ is large, $\mathrm{D} \geq 1.0 \mathrm{~m}(3.3 \mathrm{ft})$. At $\mathrm{D}=$ $1.0 \mathrm{~m}(3.3 \mathrm{ft})$ and above, the burning rate has been shown to be constant [4]. Since the isopropyl alcohol pan fires conducted at NIST were for an effective diameter of $2.1 \mathrm{~m}(6.9 \mathrm{ft})$, which is well

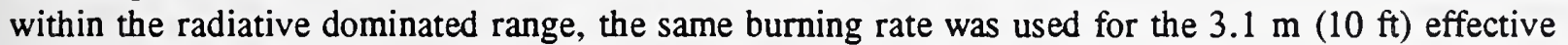
circular diameter fire conducted in the aircraft hangar. Using the above equation, the calculated heat release rate for the fire in the aircraft hangar is approximately $8250 \mathrm{~kW}(7820 \mathrm{Btu} / \mathrm{s})$.

The heat release rate as a function of time is shown in table 1. An initial growth phase of the fire was selected to provide a reasonable fit with the measured temperature rise early in the fire, as well as with test observations.

The fraction of the heat release rate that is radiated from the flaming region directly affects the gas temperature. The radiant heat fraction is sometimes referred to as $\mathrm{X}_{\mathrm{T}}$. For many common fuels with luminous flames, it has been found that the radiative fraction is 35 percent [5]. Although many alcohols burn without luminous flames, isopropyl alcohol flames are very luminous, appearing much like the flames produced from burning heptane. Since isopropyl alcohol burns with luminous flames, the analysis was performed with a radiative fraction of 35 percent.

To determine the sensitivity of the gas temperature predictions to heat release rate, a 20 percent higher heat release rate, $9900 \mathrm{~kW}(9375 \mathrm{Btu} / \mathrm{s})$ was also examined in this report. This provides a higher end prediction of the temperatures in the hangar. The higher heat release rate analysis takes into account possible uncertainties in measurement of prior tests of the burning rate performed in the NIST large calorimeter. 


\subsection{Measurements}

\subsubsection{Type of measurements taken}

Thermocouples were used to measure the gas temperatures above the fire and along the ceiling. The thermocouples were bare-bead, $0.52 \mathrm{~mm}(0.02 \mathrm{in})$ diameter, type $\mathrm{K}$, chromel-alumel thermocouples. Brass disks were used to simulate the heating of fusible links. The disks were $9.5 \mathrm{~mm}(0.38 \mathrm{in})$ diameter, $0.81 \mathrm{~mm}(0.03 \mathrm{in})$ thick brass. The RTI of the brass disks is $33.4(\mathrm{~m}-\mathrm{s})^{1 / 2}\left(60.5(\mathrm{ft}-\mathrm{s})^{1 / 2}\right)$. Figure 6 shows the instrumentation layout. The temperatures of the thermocouples and brass disks were recorded every 4 seconds on a computer-based data acquisition system.

To measure the gas temperature, six temperature measurements were taken vertically below the ceiling east of the fire at radial distances of $1.5,3.0,4.6$, and $6.1 \mathrm{~m}(5,10,15$, and $20 \mathrm{ft})$ from the centerline of the fire and west of the fire at a radial distance of $3.0 \mathrm{~m}$ from the centerline of the fire. At each radial position, a thermocouple and calibrated brass disk were placed at $0.15 \mathrm{~m}(0.5 \mathrm{ft})$ and $0.91 \mathrm{~m}(3 \mathrm{ft})$ below the ceiling. Thermocouples were also placed at $0.30 \mathrm{~m}(1.0 \mathrm{ft})$ and $1.5 \mathrm{~m}(5 \mathrm{ft})$ below the ceiling. Assuming that the smoke and temperature flow together, the thermocouple readings can indicate the initial arrival of the smoke to the thermocouple location. This assumption is supported by the experiments of Heskestad and Delichatsios [6].

To track smoke filling in the fire test curtained area, thermocouples were placed to the east and west

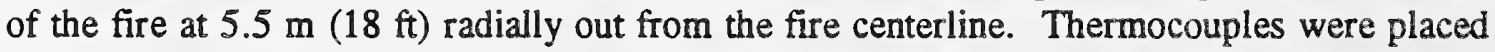
vertically from the ceiling to the bottom of the draft curtain as shown in figure 6 to determine the layer height.

To measure the centerline plume temperatures, eight thermocouples were placed directly over the fire at $0.025,3.0,6.1,9.1,12.2,15.2,18.2$, and $21.3 \mathrm{~m}(0.082,10,20,30,40,50,60$, and $70 \mathrm{ft})$ below the ceiling.

To track the flow of smoke, a thermocouple was placed $0.025 \mathrm{~m}(0.082 \mathrm{ft})$ directly under the draft curtains between the test area and the adjacent curtained areas. An array of four thermocouples was placed at the center of the east adjacent curtained area and of the west adjacent curtained area. Thermocouples were also placed $0.025 \mathrm{~m}(0.082 \mathrm{ft})$ below the draft curtains at the far end of the east adjacent curtained area and at the far end of the west adjacent curtained area. Thermocouples were placed to the north and south of the fire, at radial distances of 3.0,6.1, and $9.1 \mathrm{~m}$ from the pan centerline $(10,20$, and $30 \mathrm{ft})$, each $0.15 \mathrm{~m}(0.5 \mathrm{ft})$ below the ceiling.

\subsubsection{Uncertainty of measurements}

The manufacturer of the thermocouple wire [7] states that there is a $\pm 2.2{ }^{\circ} \mathrm{C}$ uncertainty in the thermocouple reading. The resolution of the data acquisition system is $0.3^{\circ} \mathrm{C}$. Experimental uncertainties such as re-radiation and chemical dissociation are negligible for the temperature range realized in this experiment.

The fire pulsations are reflected in the temperature fluctuations seen in the curves for measured temperature. A mean temperature for each measurement point was calculated and is reported with the associated standard deviation. This deviation is plus or minus three to seven degrees celsius depending on the location of the thermocouple. 


\subsection{COMPUTER MODELS}

The NFPA handbook groups computer fire models into two categories: enclosure fire models and special-purpose models [8]. Enclosure fire models are structured to predict the interaction of multiple fire processes involving heat transfer, fluid mechanics, and combustion chemistry occurring in an enclosure. Special purpose computer models are computer models designed for special purpose analyses such as: structural fire resistance, prediction of response time of heat detectors and automatic sprinklers, egress design, or performance of smoke control or ventilation systems. Fire models are further subdivided into probabilistic and deterministic models. Probabilistic models treat fire growth as a series of sequential events or states. Probabilities are assigned to each transfer point based on analysis of relevant experimental data and historical fire incident data. In contrast, deterministic models represent the processes encountered in a compartment fire by interrelated mathematical expressions based on physics and chemistry. According to this system classification, DETACT-QS, LAVENT, and the activation subroutine in FPETOOL are all special purpose deterministic fire models [8].

A CFD model can be used as a deterministic enclosure model. A CFD model solves the mass, energy, and momentum equations directly which provides more flexibility in modelling complex situations. In using a CFD model, the enclosure is divided up into many small spaces or grid volumes and the conservation equations are then solved to yield the values of temperature, velocity, etc. at the center of these grid volumes. CFD modelling then provides temperature and velocity distributions across the enclosure.

\subsection{DETACT-QS and FPETOOL}

It is important to understand the physics of the computer models and the assumptions built into each code. FPETOOL, written by Nelson $[9,10]$ and DETACT-QS (DETector ACTuation Quasi-Steady), written by Evans and Stroup [11,12], are each based on experimental correlations developed by Alpert for steady-state fires [13]. These correlations give the maximum temperature and maximum velocity of the ceiling jet as a function of the steady state heat release rate of the fire, the radial distance from the fire to the detector, and the height of the ceiling above the fuel. Both programs assume the detector or sprinkler is located at a distance below the ceiling corresponding to maximum temperature and velocity. Alpert's correlations assume a smooth, unconfined ceiling. They also assume that steady-state correlations can be applied to a growing fire over small time intervals. Both DETACT-QS and FPETOOL perform a linear interpolation to determine the heat release rate at intermediate times.

In both programs, the transport time of the smoke and hot gases from the fire to the thermal detector is neglected. Also in both programs, the detector is subject to the maximum temperature and velocity of the ceiling jet. FPETOOL accounts for the impact of the hot gases entrained into the ceiling jet on the temperature and velocity of the jet as it passes through the hot smoke layer; DETACT-QS does not. The expressions used in DETACT-QS and FPETOOL for temperature and velocity are based on a nondimensional parameter $r / h$, where $r$ is the radial distance from the centerline of the fire to the thermal device, and $\mathrm{h}$ is the height from the base of the fire to the ceiling. These expressions are independent of radius for $\mathrm{r} / \mathrm{h} \leq 0.18$, which is assumed to be within the plume region.

The user inputs for DETACT-QS are shown in table 2. The user inputs for FPETOOL are shown in table 3. FPETOOL version 3.01 was used. In both programs, $999^{\circ} \mathrm{C}$ is used for the response 
temperature of the device as the predicted thermal device temperature was compared to the measured temperature of the disk and not to the activation time of a sprinkler or detector, i.e., the device was programmed not to go off. FPETOOL and DETACT-QS do not model draft curtains. DETACT-QS has no walls and assumes open burning. It can not accommodate heat losses to the ceiling. To model a draft curtain using FPETOOL, the dimensions of the curtained area are used for the room spacial dimensions, the program assumes there are walls. The door/window option is then used to simulate the area under the draft curtains as large openings in the walls.

\subsection{LAVENT}

LAVENT (Link-Actuated VENT), is a program written by Davis and Cooper $[14,15]$, to simulate the environment and response of sprinkler links in compartment fires with draft curtains and fusible-linkactuated ceiling vents. LAVENT is similar to FPETOOL and DETACT-QS in that it assumes that steady state correlations can be applied to a growing fire over small time intervals; and it too neglects the transport time of the smoke and hot gases from fire to thermal detector. LAVENT does account for the impact of the hot upper layer on the ceiling jet. The important difference between LAVENT and the other activation models, is that LAVENT accounts for position of the thermal detector below the ceiling in the ceiling jet. It cannot model recessed or concealed sprinklers, as the velocity in LAVENT is zero at the ceiling. The expressions for ceiling jet temperature and velocity used in LAVENT are independent of radius for $r / h \leq 0.2$, which is assumed to be within the plume region. The expression for ceiling jet temperature and velocity as a function of height beneath the ceiling used in LAVENT are not valid in the plume region, where there are no appreciable temperature or velocity gradients below the ceiling. LAVENT will only provide an accurate temperature prediction in the $\mathrm{r} / \mathrm{h}$ 0.2 region at the point below the ceiling where the maximum temperature and velocity occur. This unfortunately must be determined by the user through trial and error, although some guidance is provided in the user guide.

LAVENT utilizes draft curtains instead of walls. LAVENT models just one curtained area. When that area fills with smoke it spills out into an infinite open space. The user inputs for LAVENT are shown in table 4.

\subsection{FLOW3D}

A computational fluid dynamic (CFD) or field model, HARWELL FLOW3D [16], was used to simulate the fires in the large spaces analyzed in this report. This model uses a finite difference method to solve the Navier Stokes equations in either two or three dimensions on a user-specified grid. The Navier-Stokes equations include mass, momentum, and energy conservation.

While the CFD model enjoys a degree of flexibility that is missing in the special purpose activation models, there are a few drawbacks to using a CFD model. The model is typically more difficult to use in that an appropriate grid must be chosen to represent the physical space, accurately solve the partial differential equations, and provide for adequate representation at the boundaries. These problems typically require thousands of grid volumes to provide accurate results. Long computation times are therefore required for CFD calculations. Fire-based CFD calculations require a turbulence model in order to simulate the gas momentum and energy flow in turbulent regions. The turbulence models now available either do not do an adequate job modelling fire plumes or have not been thoroughly tested over a large range of fires. 
For the calculations reported here, the fire is represented by a heat release rate with the energy input being distributed over several grid volumes to avoid an unrealistically large energy input in any single grid volume. The ideal gas law is used to represent the equation of state for air. Buoyancy is incorporated in the calculation by assuming that the gas is compressible and that the density is given by the ideal gas law. Fire induced turbulence is modeled using the $k-\epsilon$ model 16]. The turbulence model depends on a number of user specified parameters which are given in table 5. Wall boundary conditions are treated using the standard model for turbulent flow. Table 6 lists the key words used in the command file to activate physical models, the grid volume dimensions for some of the calculations, the ambient variables, and the key words to specify the boundary conditions used for the FLOW3D calculations.

\subsection{COMPARISON OF COMPUTER FIRE MODELS TO MEASUREMENTS}

\subsection{Plume symmetry}

Table 7 shows the measured mean temperature and standard deviation of the gas at $3.0 \mathrm{~m}(10 \mathrm{ft})$ to the east of the pan centerline and $3.0 \mathrm{~m}(10 \mathrm{ft})$ to the west of the pan centerline at a depth of $0.15 \mathrm{~m}$, $0.30 \mathrm{~m}, 0.91 \mathrm{~m}$, and $1.5 \mathrm{~m}(0.5 \mathrm{ft}, 1 \mathrm{ft}, 3 \mathrm{ft}$, and $5 \mathrm{ft})$ below the ceiling for the three experiments conducted. By comparing the east-west temperature measurements, it can be seen that the smoke plume was most symmetrical in test 2. Based on plume symmetry, test 2 was used for comparison to the predictions of the computer models.

\subsection{Gas temperatures}

Table 8 shows the steady state gas temperatures at $0,1.5,3.0,4.6,6.1$, and $12.5 \mathrm{~m}(0,5,10,15$, 20 , and $41 \mathrm{ft}$ ) radial distance from the centerline of the fire as measured in the experimental section. The measured temperature reported is the mean temperature from 32 to $100 \mathrm{~s}$. The number in parentheses following the mean temperature is the standard deviation. This time period represents quasi-steady conditions of the temperature near the ceiling.

\subsubsection{Inside the fire test curtained area}

Figures 7 and 8 show the graphical comparison of the measured and predicted gas temperatures at a radial distance of $1.5 \mathrm{~m}(5 \mathrm{ft})$ and $6.1 \mathrm{~m}(20 \mathrm{ft})$ from the centerline of the fire respectively. These radial distances correspond to non-dimensional radii $(\mathrm{r} / \mathrm{h})$ of 0.05 , and 0.2 . The measured gas temperatures are shown as solid lines. In each graph, these four solid lines represent the measured temperatures at $0.15 \mathrm{~m}, 0.30 \mathrm{~m}, 0.91 \mathrm{~m}$, and $1.5 \mathrm{~m},(0.5 \mathrm{ft}, 1 \mathrm{ft}, 3 \mathrm{ft}$, and $5 \mathrm{ft})$ below the ceiling. Since the temperatures at these four distances below the ceiling are coincident, they were not individually labeled. These curves fluctuate, which reflects the pulsation of the fire. The predictions of DETACT-QS and FPETOOL are also shown as solid lines. The predicted values are smooth and straight. Predictions of gas temperature by LAVENT are shown as various style dashed lines. Arrows on the graph point to predictions of LAVENT at vertical distances below the ceiling of $d=$ $0.15 \mathrm{~m}, 0.30 \mathrm{~m}, 0.91 \mathrm{~m}$, and $1.5 \mathrm{~m}(0.5 \mathrm{ft}, 1 \mathrm{ft}, 3 \mathrm{ft}$, and $5 \mathrm{ft})$. There is only one curve shown for DETACT-QS and FPETOOL at each radial distance as these programs do not account for the vertical distance below the ceiling. 
Measurement locations from the fire centerline through $6.1 \mathrm{~m}(20 \mathrm{ft})$ radial distance from the fire are within the fire test curtained area as shown in figure 6 . For these locations, the $\mathrm{r} / \mathrm{h}$ values are all 0.2 or less. For $r / h \leq 0.2$, the temperature predictions of the computer fire models do not change.

DETACT-QS and FPETOOL underpredict the excess temperature (temperature rise above the ambient value of $22^{\circ} \mathrm{C}$ ) by $34: 41$ percent (depending on the radial distance from the fire centerline) when compared to the measured values averaged over a $32-100$ second time interval. It can also be observed from these graphs, that the predictions of LAVENT nearer to the ceiling are closer to the measured values, and thus more accurate than the DETACT-QS or FPETOOL values. However, for positions further from the ceiling, the predictions of LAVENT are less accurate than DETACT or FPETOOL. This is due to the measurement locations being inside the plume. The correlations for ceiling jet velocity and temperature as a function of distance below the ceiling used in LAVENT are not valid inside the plume, and thus the user must be careful not to use this parameter for locations within the plume. This phenomena is illustrated in figure 9.

However, for high bay areas, often the location of interest is an $r / h \leq 0.2$ due to the ceiling height. Therefore, when running LAVENT inside the plume, the user should use only the prediction at the position below the ceiling corresponding to the maximum temperature and velocity. This position must be found through trial and error, although some guidance is provided in [14]. LAVENT at the point below the ceiling where the temperature is maximum (approximately $0.15 \mathrm{~m}$ below the ceiling in this case) underpredicts the excess temperature by $6-16$ percent when compared to the measured values averaged over a 32 - 100 second time interval. Future versions of LAVENT should be upgraded so that the computer program does not calculate for a ceiling jet (temperature gradient in the vertical direction) for $\mathrm{r} / \mathrm{h} \leq 0.2$.

Considering the above mentioned problems with the predictions of the computer fire models, it may be useful to use the plume correlations for the plume centerline temperatures to determine the temperature rise above ambient for locations inside the plume region. These plume correlations assume burning in the open (i.e., no ceiling), and thus free entrainment. There are a number of prediction methods available for plume temperature, in general producing very similar results. For comparisons performed here, the prediction methods of McCaffrey were selected [18]

$$
\Delta T_{0}=\left(\frac{T_{0}}{2 g}\right)\left(\frac{k}{C}\right)^{2}\left(\frac{z}{\dot{Q}^{2 / s}}\right)^{2 \eta-1}
$$

where:

$\Delta \mathrm{T}_{0}=$ centerline temperature rise above ambient $(\mathrm{K})$

$\mathrm{T}_{\mathrm{o}}=$ ambient temperature $(\mathrm{K})$

$\mathrm{g}=$ acceleration due to gravity $\left(\mathrm{m} / \mathrm{s}^{2}\right)$

$\mathrm{C}=$ constant, 0.9

$\mathrm{z}=$ height above base of fire $(\mathrm{m})$

$\dot{Q}=$ heat release rate of the fire $(\mathrm{kW})$

$\mathrm{k}$, and $\eta$ are constants whose value depends on weather the location of interest is within the flame, intermittent, or plume region of the fire. This is determined by the factor $z / \dot{Q}^{2 / 5}\left(\mathrm{~m} / \mathrm{kW}^{2 / 5}\right)$. If $\mathrm{z} / \dot{\mathrm{Q}}^{2 / 5}$ 
is $<0.08$, it is considered that this location is in the flaming region of the fire. In this region, $\mathrm{k}=$ $6.8 \mathrm{~m}^{1 / 2} / \mathrm{s}$, and $\eta=1 / 2$. If $\mathrm{z} / \mathrm{Q}^{2 / 5}$ is between $0.08-0.2$, it is considered that this location is in the intermittent region of the fire. In the intermittent region, $\mathrm{k}=1.9 \mathrm{~m} / \mathrm{kW}^{1 / 5} \mathrm{~s}$, and $\eta=0$. If $\mathrm{z} / \mathrm{Q}^{2 / 5}$ is $>0.2$, it is considered that this location is in the plume region of the fire as is the case for the calculations near the ceiling. In the plume region of the fire, $\mathrm{k}=1.1 \mathrm{~m}^{4 / 3} / \mathrm{kW}^{1 / 3}$.s and $\eta=-1 / 3$.

The plume theory of McCaffrey predicts a temperature gradient from $0.025 \mathrm{~m}$ to $1.5 \mathrm{~m}$ below the ceiling of only $2{ }^{\circ} \mathrm{C}$, which compares well with the measured temperatures which were coincident within the uncertainty band. The predicted temperature at $0.025 \mathrm{~m}$ below the ceiling is $53{ }^{\circ} \mathrm{C}$ and at $1.5 \mathrm{~m}$ below the ceiling is $55^{\circ} \mathrm{C}$. The predicted temperature at $0.025 \mathrm{~m}$ below the ceiling represents an underprediction of the excess temperature by 21 percent when compared to the measured value averaged over a 32 - 100 second time interval.

Figure 10 shows the measured gas temperatures along the ceiling, $0.15 \mathrm{~m}(0.5 \mathrm{ft})$ below the ceiling at radial distances of $0,1.5,3.0$, and $4.6 \mathrm{~m}(0,5,10$, and $15 \mathrm{ft})$. It can be seen that there is no measured temperature gradient within the plume.

\subsubsection{Outside the fire test curtained area}

The measurement location at a radial distance of $12.5 \mathrm{~m}(41 \mathrm{ft})$ from the centerline of the fire, corresponding to a nondimensional radius of $\mathrm{r} / \mathrm{h}=0.41$, is outside the plume region and on the other side of the fire test curtained area. None of the computer programs account for the flow around the draft curtains, thus this location can not be modeled accurately with present computer fire models. To model the draft curtain, and the flow around the curtain, a computational fluid dynamics model is necessary.

\subsubsection{Sensitivity to Heat Release Rate}

As was discussed in section 2.2 of this report, an analysis was conducted to determine the sensitivity of model predictions to the heat release input. Temperature predictions of the models were determined using a 20 percent higher heat release rate of $9900 \mathrm{~kW}(9380 \mathrm{Btu} / \mathrm{s})$. Figure 11 shows the DETACT-QS, FPETOOL, and LAVENT predictions for the higher heat release rate at the $6.1 \mathrm{~m}$ radial distance compared to the experimental data. This figure can be compared to figure 8 which shows the temperatures predicted for the same location with a heat release rate of $8250 \mathrm{~kW}$. FPETOOL and DETACT-QS predicted a 9 percent $\left(2{ }^{\circ} \mathrm{C}\right)$ higher excess temperature for the 20 percent higher heat release rate. LAVENT predicted an $11-13$ percent $\left(2-4^{\circ} \mathrm{C}\right)$ increase in excess temperature. The higher heat release rate did change the temperature predictions; however, it did not change the overall results. That is, DETACT-QS and FPETOOL still underpredicted the gas temperatures. LAVENT predicted the temperatures well (closer to the experiment) at the position below the ceiling corresponding to the maximum temperature and velocity.

\subsection{Hot gas transport time}

The measured gas temperatures at the pan centerline, $1.5 \mathrm{~m}, 3.0 \mathrm{~m}, 4.6 \mathrm{~m}(5 \mathrm{ft}, 10 \mathrm{ft}, 15 \mathrm{ft})$ and out

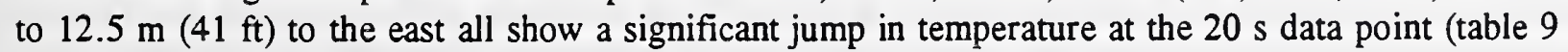
givestime to first response of the thermocouples) that had not registered at the $16 \mathrm{~s}$ data point. This tells us that the smoke plume reached these points $18 \pm 2$ seconds after ignition. It is impossible to determine more exactly than the resolution of the data recorder. Also, the thermocouple $3.0 \mathrm{~m}(10 \mathrm{ft})$ 
to the west of the pan centerline registered an increase in temperature 20 seconds after ignition. The thermocouple measurements combined with visual test observations, suggest the plume width to be approximately $16 \mathrm{~m}(52 \mathrm{ft})$. The calculated plume width (using Heskestad's plume theory) at the ceiling is $15 \mathrm{~m}$ (49 ft) which agrees with this result. [19]

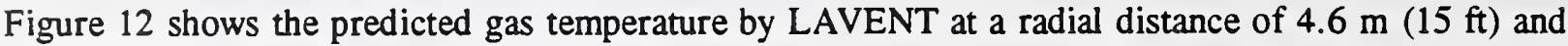
$0.15 \mathrm{~m}(0.5 \mathrm{ft})$ below the ceiling. This location was chosen because the measured temperature matched the predicted temperature so closely. Also shown in figure 12 is the same gas temperature prediction shifted 18 seconds to the right. The 18 second shift was selected to match the times of the predicted gas temperature rise to the times of the measured temperature rises. None of the computer fire models account for the transport time in the plume so changes in the input fire immediately affect the predicted temperatures at the ceiling. A similar shift could be applied to the FPETOOL and DETACT-QS results.

\subsection{COMPARISON OF FIELD MODEL (CFD) CALCULATIONS TO MEASUREMENTS}

The $30.4 \mathrm{~m}(100 \mathrm{ft})$ hangar curtained area was modelled using a heat source to simulate the pan fire. Computer speed effectively limits the total number of grid volumes available to model the problem. It was assumed that all the heat was released in the sixteen model grid volumes situated directly over the pan. Due to the size of the enclosure, only a portion of the curtained area was modelled. To reduce the number of grid volumes by a further factor of two, it was assumed that the fire was symmetric about a plane passing through the fire center and parallel to the draft curtains.

Initial modelling efforts concentrated on the gas flow interacting with the draft curtains and assumed that the open trusses would have minimal impact on the gas flow. Heat flow to the ceiling was initially ignored due to the low expected temperatures at the ceiling. Later calculations included a conducting ceiling. Thermocouple measurements prior to the fire indicated that there was only a small thermal gradient present in the hangar.

Several grid volume sizes were used in an effort to determine what effects, if any, were caused by the grid volume coarseness. A section view of the three dimensional grid used for some of the runs discussed later in the paper is displayed in figure 13. The grid structure is nonuniform in an attempt to maximize the grid volumes in regions where the temperature gradients are largest or where small structures are modelled. Details of the grid dimensions are given in table 7.

Since the curtained area was not modelled in its entirety, pressure boundary conditions were used to bound the modelling regime at gas interfaces. At a pressure boundary condition, it is assumed that the inward or outward flow is continuous with upstream values of temperature, scalars, and turbulence used if flow is outward and ambient values used if flow is inward. The pressure boundaries were kept a minimum of twelve grid volumes away from the edge of the fire in order to minimize any error introduced by these boundaries.

One of the major decisions in modelling the fire induced plume was the choice of turbulence model used in the calculation. For this work, the $k-\epsilon$ model was used. This model has a number of user specified parameters which affect the ultimate viscosity and heat transfer in the plume. A number of investigators have proposed sets of parameters for the $k-\epsilon$ model $[20,21]$. The default values used in the CFD model, HARWELL FLOW3D, for $C_{1}, C_{2}$ and $C_{\mu}$ are the parameters first proposed by 
Launder and Spalding [17]. For buoyant plumes, an additional term, $\mathrm{C}_{3}$, to account for the production/destruction of turbulence due to buoyancy may be included. Additional changes have been proposed for some of the constants in order to match existing plume correlations with CFD modelling. Several sets of parameters for the $\mathrm{k}-\epsilon$ model, see table 6 , were used in modelling the hangar fire.

In modelling the fire for these calculations, it was assumed that 35 percent of the total heat release rate was radiated from the plume at the fire source. The remaining 65 percent was then used as the convective heat release rate which provided the energy to drive the fire plume flow. The 35 percent radiative loss rate has been the standard value found in many computer fire models. For this fire, as mentioned earlier, the radiative loss rate may range from 20 to 35 percent [5].

The plume centerline temperature was determined in the following way. Unlike the thermocouple measurements fixed near the ceiling which maintained roughly constant temperatures throughout the first 150 seconds of the experiment, the thermocouples suspended at the geometrical plume center did not reach constant temperatures until about 100 seconds into the experiment. Visual inspection of the videotape suggests that the swaying of the thermocouple tree and some plume asymmetry may be responsible for the lack of constant temperatures early in the measurement. Therefore, the plume centerline temperature was obtained by averaging the thermocouple measurements taken between 100 and 120 seconds which should give a "steady state" plume centerline temperature profile for the fullyinvolved pan fire.

Figure 14 displays a comparison of the calculated and measured plume centerline temperatures as a function of height above the floor for each set of turbulence constants. The calculations are based on a time of 45 seconds after the start of the fire with time zero equal to $8250 \mathrm{~kW}(7810 \mathrm{Btu} / \mathrm{s})$. The standard $k-\epsilon$ constants with no buoyancy, $k 34$, consistently underpredict the centerline temperature and while the shape of the temperature profile in the lower plume is simulated, the upper plume is not well represented. Including the buoyancy term, $\mathrm{k} 35$, causes the model to overpredict the centerline temperatures and produces a much poorer agreement with height. Modifying two of the standard constants, calculations $\mathrm{k} 36$ and $\mathrm{k} 38$ provide better agreement with the temperature near the ceiling, but poor agreement with the overall shape of the centerline temperature.

A comparison of the experimental data to the McCaffrey and Heskestad correlations [18,19] for plume centerline temperature are given in figure 15. The correlations, which are based on experimental measurements conducted in smaller spaces and axisymmetric conditions do not adequately represent the present data. The shape of the centerline profile does not provide for the flat temperature profile near the ceiling observed in the experiment. Calculations k34 - k38 are also compared with the McCaffrey result in figure 16. Calculations based on the turbulence constants used for $\mathrm{k} 36$ and $\mathrm{k} 38$ provide the best agreement with the McCaffrey correlation.

One of the major difficulties in modelling the hangar is that the roof area is not only partitioned by draft curtains but also contains a number of beams, as mentioned earlier, which could act as additional smoke blockages and could account for at least part of the flat temperature profile observed near the ceiling. Figure 17 displays a comparison of a CFD calculation using the turbulence constants of k36 with the experimental data. For this calculation, the grid volumes were made smaller near the ceiling such that the $3.7 \mathrm{~m}$ (12 ft) draft curtain was described by 12 grid volumes rather than three as was done in the earlier calculations. The adiabatic assumption was relaxed and the ceiling was assumed to be conducting and made of steel which was assumed to be of thickness of $0.15 \mathrm{~m}(0.5 \mathrm{ft})$. 
While the inside of the ceiling was corrugated steel, the makeup of the ceiling above the corrugation was not obtainable. Over the duration of the calculation, $30 \mathrm{~s}$, the material above the steel was unimportant. It should be noted that the earlier calculations were run for $45 \mathrm{~s}$ while this calculation was run for $30 \mathrm{~s}$. The shorter run time was used for the larger number of grid volumes after verifying, using the smaller number of grid volumes, that the calculation had essentially reached steady state at $30 \mathrm{~s}$. Also included in the calculation were large I-beams which ran perpendicular to the draft curtain at the ceiling and effectively converted each ceiling compartment into a square. The additional framing trusses near the ceiling and the additional I-beams running perpendicular and parallel to the draft curtain at an elevation about $24 \mathrm{~m}(79 \mathrm{ft})$ above the floor were not modelled. These modifications provided an improvement to the calculation with the predicted temperature closer to the measured temperature near the ceiling and the deviation in shape away from the measured temperature being smaller at the lower elevations.

The observation that both the plume correlations and the CFD computation suggest that the plume temperature should decrease with increasing height from the floor rather than remain a constant as was measured suggests that the experiment or the building geometry needs to be re-examined. While the draft curtains and ceiling beams may play some role in the temperature remaining constant near the ceiling, they should not provide much of an effect at heights equal to one-half the ceiling height for a building of this size at times early in the experiment. The explanation for the temperature variation with height may be experimental in nature. One possibility is that the plume is not maintaining a completely vertical rise. In this case, thermocouples located at distances between 15 and $25 \mathrm{~m}$ (49 and $82 \mathrm{ft}$ ) above the floor could be sampling parts of the plume that are cooler than at the centerline of the plume. Depending on how much the plume has swayed, a constant temperature profile with height could be experimentally produced using a single string of thermocouples located at the geometrical center of the fire as was done in this experiment. Based on plume correlations, the temperature half-width should be $1.9 \mathrm{~m}(6.2 \mathrm{ft})$ at the $15 \mathrm{~m}(49 \mathrm{ft})$ height above the floor. Over a 15 $\mathrm{m}$ (49 ft) length, for the plume to sway $1.9 \mathrm{~m}(6.2 \mathrm{ft})$ requires an angle of about 7 degrees as measured from the floor. Closer to the ceiling, the temperature half-width for the plume would be larger and the averaging effect would be less noticeable. Unfortunately, additional thermocouples were not available to check the plume symmetry at lower elevations. Visual inspection of the plume using the video playback suggests that the plume is fairly vertical but visual observations are line of sight dependent and particularly suspect when small angles are involved. Inspection of the fiame in figure 5 suggests that there is some kinking of the flame which may continue upward until the plume impinges at the ceiling. If the thermocouples are sampling across the plume diameter rather than the plume centerline, lower average temperatures will be obtained.

A second possibility would be the sway of the thermocouple tree in response to the turbulence of the plume thus again sampling a lower average temperature than the maximum centerline temperature. The raw data shows a large variation of measured temperature with time indicating the unsteady nature of the measurement. Inspection of the videotapes indicate that the thermocouple tree was swaying in response to the fire turbulence. Whether these temperature variations were in part a response to the thermocouple tree swaying in the plume cannot be determined using the limited instrumentation associated with the plume.

A third possibility would be a pre-existing temperature stratification which would slow the plume, inhibit entrainment and possibly produce a constant temperature profile. The measured temperature stratification is at most $2{ }^{\circ} \mathrm{C}$; hence, the plume should not have lost enough buoyancy to produce the observed experimental effect. 
To summarize the results of this comparison, the CFD calculation using either $k 36$ or $k 38$ turbulence constants provide a fair representation of the plume centerline temperature at the ceiling. The more detailed grid volume CFD calculation provides a better representation of the plume centerline temperature near the ceiling than either the earlier CFD calculations or the two plume correlations.

Temperature measurements along the ceiling between the plume center and the draft curtain were fairly constant in the experiment with the average temperature in the interval between 30 - 50 seconds only decreasing by about $4{ }^{\circ} \mathrm{C}$ for measurements $0.15 \mathrm{~m}(0.5 \mathrm{ft})$ beneath the ceiling. The CFD calculations at 39 seconds using the more detailed grid volumes at $0.15 \mathrm{~m}(0.5 \mathrm{ft})$ beneath the ceiling gave a dip of $14{ }^{\circ} \mathrm{C}$ as shown in figure 18 . At $12.6 \mathrm{~m}(41.3 \mathrm{ft})$, which is beyond the draft curtain, the temperature drops substantially for both the experimental measurement and the calculation with the calculated temperature in good agreement with the experiment at this location.

\subsection{RESULTS AND CONCLUSIONS}

1. Inside the plume region, within the curtained area, both the FPETOOL and DETACT-QS computer programs significantly underpredict the gas temperatures. The correlations of Heskestad and $\mathrm{McC}$ affrey, and the calculation using the maximum temperature predicted by LAVENT also underpredicted the gas temperatures but were closer to the measured values.

2. The CFD calculation using the modified $k-\epsilon$ parameter provided the best agreement with experiment.

3. For large spaces, a hot gas transport time delay should be incorporated into DETACT-QS, FPETOOL, and LAVENT.

4. Established plume theory correlations such as those of McCaffrey for plume temperature and velocity in the $\mathrm{r} / \mathrm{h}<0.2$ region need to be incorporated into the three computer fire models studied, since for high bay spaces the sprinkler or detector of interest would normally be located in this region.

5. Reasonable agreement was found between the field model calculations using modified $\mathrm{k}-\epsilon$ constants and the measured centerline plume temperatures near to the ceiling. Further from the ceiling, the agreement between the calculations and the measurement was not as good.

6. Reasonable agreement was found between the CFD calculation and temperature measurements along the ceiling. The temperature jump across the draft curtain can be qualitatively reproduced by the CFD calculation. 


\subsection{REFERENCES}

1. Walton, W.D., and Notarianni, K.A., "A Comparison of Ceiling Jet Temperatures Measured in an Aircraft Hangar Test Fire with $\mathrm{I}$ :mperatures Predicted by the DETACT-QS and LAVENT Computer Models", NISTIR 4947, National Institute of Standards and Technology, Gaithersburg, MD, 1992.

2. Babrauskus, V., Tables and Charts. In: Cote, A.E. ed, Fire Protection Handbook, National Fire Protection Association, Quincy, MA, Sixteenth Edition, 1986. p. 5-119.

3. Babrauskus, V., Burning Rates. In: DiNenno, P. J. ed, SFPE Handbook of Fire Protection Engineering, Society of Fire Protection Engineering, Boston, MA, First Ed., 1988. p. 2-3.

4. Drysdale, D., An Introduction to Fire Dynamics, John Wiley and Sons, N.Y., 1985. p. 155.

5. Walton, W.D., and Thomas, P.H., Estimting Temperatures in Compartment Fires. In: DiNenno, P. J. ed, SFPE Handbook of Fire Protection Engineering, Society of Fire Protection Engineering, Boston, MA, First Ed., 1988. p. 2-18.

6. Heskestad, G, and Delichatsios, M. A., Environments of Fire Detectors - Phase II: Effect of Ceiling Configuration. Volume I. Measurements. NBS-GCR-78-128, 1978. p. 1

7. The Temperature Handbook, Omega Engineering, Inc., Stamford, Conn., 1992

8. Walton, W.D., and Budnick, E.K., Deterministic Computer Fire Models. In Cote, A.E. ed., Fire Protection Handbook, National Fire Protection Association, Boston, MA, 17th Ed., 1991. p. 10-86.

9. Nelson, H.E., FPETOOL: Fire Protection Engineering Tools for Hazard Estimation, NISTIR 4380, National Institute of Standards and Technology, Gaithersburg, MD 1990.

10. Nelson, H.E., FPETOOL User's Guide, NISTIR 4439, National Institute of Standards and Technology, Gaithersburg, MD 1990.

11. Evans, D., and Stroup, D. W., "Methods to Calculate the Response Time of Heat and Smoke Detectors Installed Below Large Unobstructed Ceilings," NBSIR 85-3167, National Bureau of Standards, Gaithersburg, MD, 1985.

12. Stroup, D. W., Evans, D.D., and Martin, P.M., Evaluating Thermal Fire Detection Systems, NBS SP 712, National Bureau of Standards, Gaithersburg, MD, 1986.

13. Alpert, R.L., Calculation of Response Time of Ceiling Mounted Fire Detectors, Fire Technology, Volume 8 Number 3, August, 1972.

14. Davis, W.D., and Cooper, L.Y., Estimating the Environment and the Response of Sprinkler Links in Compartment Fires With Draft Curtains and Fusible Link-Actuated Ceiling Vents. Part 2. User Guide for the Computer Code LAVENT., NISTIR 89-4122, National Institute of Standards and Technology, Gaithersburg, MD, 1989. 
15. Davis, W.D., LAVENT: Link-Activated VENTs., SFPE Bulletin, Society of Fire Protection Engineers, Boston, MA, March/April, 1992.

16. FLOW3D Release 3.2: USER MANUAL, CFD department, AEA Industrial Technology, Harwell Laboratory, United Kingdom, October, 1992.

17. Launder, B. E. and Spalding, D. B., 1974, The Numerical Computation of Turbulent Flows, Computer Methods in Applied Mechanics and Engineering 3, North-Holland Publishing Company, pp. $269-289$.

18. Drysdale, D., An Introduction to Fire Dynamics, John Wiley and Sons, N.Y., 1985. p. 135.

19. Heskestad, G., Fire Plumes. In: DiNenno, P. J. ed, SFPE Handbook of Fire Protection Engineering, Society of Fire Protection Engineering, Boston, MA, First Ed., 1988. p. 1-107.

20. Nam, S. and Bill, R.G., Jr., Numerical Simulation of Thermal Plumes in Pool Fires, Tech. Report FMRC J.I. OROJZ.RA(2), Factory Mutual Research Corporation, Norwood, MA, June, 1991.

21. Pivovarov, M. A., Zhang, H., Ramaker, D. E., Tatem, P. A. and Williams, F. W., 1993, Similarity Solutions in buoyancy-controlled Turbulent diffusion Flame Modelling, Combustion and Flame, Vol 92, pp. $308-319$. 
Table 1.

\begin{tabular}{|c|c|}
\hline \multicolumn{2}{|c|}{ Heat Release Rate as a Function of Time } \\
\hline Time (s) & Energy (kW) \\
\hline 0 & 0 \\
5 & 4100 \\
8 & 8250 \\
200 & 8250 \\
\hline
\end{tabular}

Table 2.

\section{DETACT-QS Input Values}

Height of Ceiling Above Fuel (m)

Distance of Detection from Axis of Fire (m) $0,1.5,3.0,4.6,6.1,12.5$

Initial Room Temperature $\left({ }^{\circ} \mathrm{C}\right.$ ) 
Table 3.

\begin{tabular}{|c|c|}
\hline FPETOOL Input Values ${ }^{*}$ & \\
\hline ROOM & \\
\hline SPACIAL DIMENSIONS & \\
\hline Ceiling Height (m) & 30.4 \\
\hline Room Length (m) & 81 \\
\hline Room Width (m) & 12.5 \\
\hline LINING MATERIALS (CEILING AND WALL) & \\
\hline Material & steel \\
\hline Thermal Conductance & \\
\hline$(\mathrm{kW} / \mathrm{m}-\mathrm{K})$ & 0.043 \\
\hline Density $\left(\mathrm{kg} / \mathrm{m}^{2}\right)$ & $7.85 E+03$ \\
\hline Specific Heat & \\
\hline$(\mathrm{kJ} / \mathrm{kg}-\mathrm{K})$ & 0.48 \\
\hline Thickness (mm) & 100 \\
\hline SPRINKLER & \\
\hline $\operatorname{RTI}(\mathrm{m} / \mathrm{s})^{1 / 2}$ & 33.4 \\
\hline Response Temperature $\left({ }^{\circ} \mathrm{C}\right)$ & 999 \\
\hline Radial Distance (m) & $0,1.5,3 \cdot 0,4 \cdot 6,6.1,12.5$ \\
\hline SPRINKLER IS NOT A SIDEWALL & \\
\hline FIRE $^{1}$ & \\
\hline Fire Height (m) & 0.15 \\
\hline Heat of Combustion $(\mathrm{kJ} / \mathrm{kg})$ & $30 ; 450$ \\
\hline Rate of Heat Release & see table 1 \\
\hline VENTS & \\
\hline DOOR/WINDOW & \\
\hline Opening Height (m) & 26.8 \\
\hline Opening Width (m) & 162 \\
\hline Sill Height & 0 \\
\hline
\end{tabular}

*No smoke detectors, HVAC, or program halts defined.

${ }^{1}$ Fire parameters listed are those differing from defaults program. 
Table 4.

\begin{tabular}{|c|c|}
\hline \multicolumn{2}{|l|}{ LAVENT Input Values } \\
\hline \multicolumn{2}{|l|}{ ROOM PROPERTIES } \\
\hline Ceiling Height ( $\mathrm{m})$ & 30.4 \\
\hline Room Length ( m) & 12.5 \\
\hline Room Width ( m) & 81 \\
\hline Number of Vents & 0 \\
\hline Curtain Length ( m) & 162 \\
\hline \multicolumn{2}{|l|}{ Height for bottom } \\
\hline of Curtains (m) & 26.8 \\
\hline \multicolumn{2}{|l|}{ PHYSICAL PROPERTIES } \\
\hline Ambient Temperature $(\mathrm{K})$ & 295 \\
\hline Material & bare metal deck \\
\hline Material Thickness (m) & 0.1 \\
\hline \multicolumn{2}{|l|}{ OUTPUT PARAMETERS } \\
\hline Final Time (s) & 200 \\
\hline Output Interval (s) & 10 \\
\hline \multicolumn{2}{|l|}{ FUSIBLE LINK PROPERTIES } \\
\hline Radial Distance (m) & $0,1.5,3 \cdot 0,4.6,6.1$ \\
\hline Distance Below Ceiling (m) & $0.15,0.30,0.91,1.5$ \\
\hline Radial Distance (m) & 12.5 \\
\hline Distance Below Ceiling (m) & $0.025,1.2,2.4,3.7$ \\
\hline Radial Distance (m) & 0 \\
\hline Distance Below Ceiling ( $\mathrm{m}$ ) & 0.025 \\
\hline $\mathrm{RTI}(\mathrm{m}-\mathrm{s})^{1 / 2}$ & 33.4 \\
\hline Fuse Temperature $(\mathrm{K})$ & 999 \\
\hline \multicolumn{2}{|l|}{ FIRE PROPERTIES } \\
\hline Fire Height (m) & 0.15 \\
\hline Fire Diameter (m) & 3.088 \\
\hline Fire Output as Function of Time & see table 1 \\
\hline SOLVER PROPERTIES & program defaults \\
\hline
\end{tabular}


Table 5.

\begin{tabular}{|c|c|c|c|c|c|c|}
\hline \multicolumn{7}{|c|}{ Numerical Trials } \\
\hline Trial & $\mathrm{C}_{1}$ & $\mathrm{C}_{2}$ & $\mathrm{C}_{3}$ & $\mathrm{C}_{\mu}$ & $\begin{array}{c}\text { Prandtl Number } \\
\text { For Enthalpy }\end{array}$ & CAPPA \\
\hline K 34 & 1.44 & 1.92 & 0 & 0.09 & 0.9 & 0.419 \\
K 35 & 1.44 & 1.92 & 1 & 0.09 & 0.9 & 0.419 \\
K 36 & 1.44 & 1.92 & 1 & 0.18 & 0.85 & 0.419 \\
K 38 & 1.44 & 1.92 & 1 & 0.15 & 0.85 & 0.419 \\
\hline
\end{tabular}

Table 6.

\begin{tabular}{|c|c|c|c|}
\hline \multicolumn{4}{|c|}{ FLOW 3D INPUTS } \\
\hline \multicolumn{4}{|c|}{ MODEL PHYSICS } \\
\hline \multicolumn{4}{|c|}{ Turbulent Flow (k- $\epsilon$ Model) } \\
\hline \multicolumn{4}{|c|}{ Compressible Flow } \\
\hline \multicolumn{4}{|c|}{ Heat Transfer } \\
\hline \multicolumn{4}{|c|}{ Buoyant Flow } \\
\hline \multicolumn{4}{|c|}{ Transient Flow } \\
\hline & \multicolumn{3}{|c|}{ GRID VOLUME DIMENSION } \\
\hline & \multicolumn{3}{|c|}{$21 \times 28 \times 90$ grid volumes } \\
\hline $\mathrm{x}:$ & $13 * 0.6858 \mathrm{~m}$ & $8 * 1.3716 \mathrm{~m}$ & \\
\hline y: & $10 * 1.3716 \mathrm{~m}$ & $8 * 0: 6858 \mathrm{~m}$ & $10 * 1.3716 \mathrm{~m}$ \\
\hline z: & $40 * 0.1524 \mathrm{~m}$ & $30 * 0.6096 \mathrm{~m}$ & $20 * 0.3048 \mathrm{~m}$ \\
\hline \multicolumn{4}{|c|}{ AMBIENT VARIABLES } \\
\hline & Velocity $(\mathrm{m} / \mathrm{s})$ & & 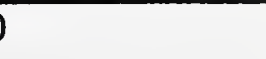 \\
\hline \multicolumn{4}{|c|}{ Gauge } \\
\hline \multicolumn{4}{|c|}{ Pressure $(\mathrm{Pa})$} \\
\hline & Density $\left(\mathrm{kg} / \mathrm{m}^{3}\right)$ & \multicolumn{2}{|c|}{1.2} \\
\hline & Viscosity $(\mathrm{kg} / \mathrm{m}-\mathrm{s})$ & \multicolumn{2}{|c|}{$1.91 \mathrm{E}-05$} \\
\hline & $\mathrm{K}(\mathrm{J})$ & \multicolumn{2}{|c|}{$1.00 \mathrm{E}-10$} \\
\hline & $\epsilon(\mathrm{J} / \mathrm{s})$ & \multicolumn{2}{|c|}{$1.00 \mathrm{E}-11$} \\
\hline & Temperature $(\mathrm{K})$ & \multicolumn{2}{|c|}{295} \\
\hline & \multicolumn{3}{|c|}{ BOUNDARY CONDITIONS } \\
\hline & \multicolumn{3}{|c|}{ Pressure Boundary (Sides) } \\
\hline & \multicolumn{3}{|c|}{ Solid (floor and non-conducting ceilings) } \\
\hline & \multicolumn{3}{|c|}{ Conducting Solid (for conducting ceilings) } \\
\hline
\end{tabular}


Table 7.

\begin{tabular}{|c|c|c|c|c|c|c|c|}
\hline \multicolumn{9}{|c|}{ Plume Symmetry } \\
\hline \multicolumn{2}{|c|}{} & \multicolumn{3}{|c|}{ Mean Temp ${ }^{\circ} \mathrm{C}(32-200 \mathrm{~s})$} & \multicolumn{3}{|c|}{ Standard Deviation } \\
\hline Location & $\begin{array}{c}\text { Depth Below } \\
\text { Ceiling (m) }\end{array}$ & Test 1 & Test 2 & Test 3 & Test 1 & Test 2 & Test 3 \\
\hline East 3.0 m & 0.15 & 63 & 59 & 64 & 7 & 6 & 7 \\
from pan & 0.3 & 60 & 55 & 61 & 7 & 6 & 7 \\
centerline & 0.91 & 63 & 61 & 65 & 6 & 4 & 6 \\
& 1.5 & 63 & 61 & 65 & 7 & 5 & 7 \\
\hline West 3.0 m & 0.15 & 53 & 59 & 57 & 4 & 6 & 5 \\
from pan & 0.3 & 50 & 55 & 54 & 4 & 6 & 5 \\
centerline & 0.91 & 52 & 58 & 57 & 4 & 5 & 4 \\
& 1.5 & 49 & 54 & 54 & 4 & 5 & 6 \\
\hline
\end{tabular}


Table 8.

\begin{tabular}{|c|c|cc|}
\hline \multicolumn{4}{|c|}{ Mean Gas Temperatures $(32-100 \mathrm{~s})$} \\
\hline Location & $\begin{array}{c}\text { Depth Below } \\
\text { Ceiling }(\mathrm{m})\end{array}$ & $\begin{array}{c}\mathrm{T}_{\text {measured }} \\
(\mathrm{C})\end{array}$ & $\begin{array}{c}\text { Standard } \\
\text { Deviation }\end{array}$ \\
Centerline & & & \\
$0 \mathrm{~m}$ & 0.025 & 64 & $(6)$ \\
\hline East $1.5 \mathrm{~m}$ & 0.15 & 61 & $(6)$ \\
$(\mathrm{r} / \mathrm{h}=0.05)$ & 0.3 & 59 & $(6)$ \\
& 0.91 & 63 & $(5)$ \\
& 1.5 & 62 & $(5)$ \\
\hline East 3.0 m & 0.15 & 59 & $(6)$ \\
$(\mathrm{r} / \mathrm{h}=0.1)$ & 0.3 & 55 & $(6)$ \\
& 0.91 & 61 & $(4)$ \\
& 1.5 & 61 & $(5)$ \\
\hline East 4.6 m & 0.15 & 57 & $(5)$ \\
$(\mathrm{r} / \mathrm{h}=0.15)$ & 0.3 & 55 & $(7)$ \\
& 0.91 & 59 & $(4)$ \\
& 1.5 & 57 & $(5)$ \\
\hline East 6.1 m & 0.15 & 59 & $(4)$ \\
$(\mathrm{r} / \mathrm{h}=0.20)$ & 0.3 & 59 & $(4)$ \\
& 0.91 & 64 & $(6)$ \\
& 1.5 & 63 & $(5)$ \\
\hline East 12.5 m & 0.025 & 33 & $(4)$ \\
$(\mathrm{r} / \mathrm{h}=0.41)$ & 1.2 & 35 & $(3)$ \\
& 2.4 & 42 & $(7)$ \\
& 3.7 & 34 & $(5)$ \\
\hline
\end{tabular}


Table 9.

\begin{tabular}{|c|c|}
\hline \multicolumn{2}{|c|}{ Hot Gas Transport Time } \\
\hline $\begin{array}{c}\text { Radial Distance } \\
\text { From Pan Centerline (m) }\end{array}$ & $\begin{array}{c}\text { Time to } \\
\text { Response (s) }\end{array}$ \\
\hline 0 & 20 \\
East 1.5 & 20 \\
East 3.0 & 20 \\
East 4.6 & 20 \\
East 6.1 & 20 \\
East 6.2 (under draft curtain) & 20 \\
East 12.5 & 20 \\
East 18.9 (under draft curtain) & 44 \\
\hline & \\
\hline West 3.0 & 20 \\
West 5.5 & 24 \\
\hline
\end{tabular}




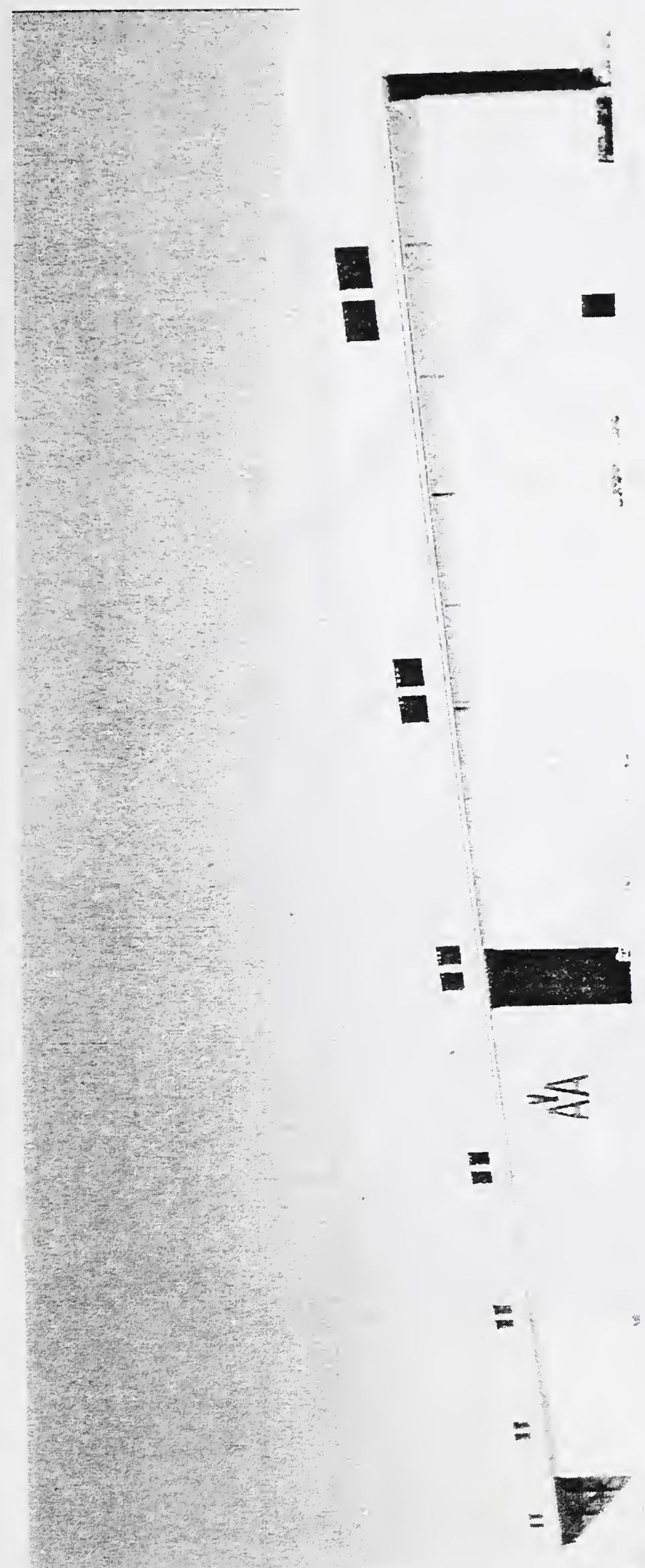

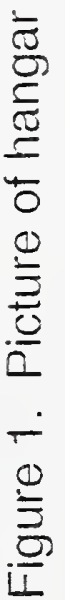




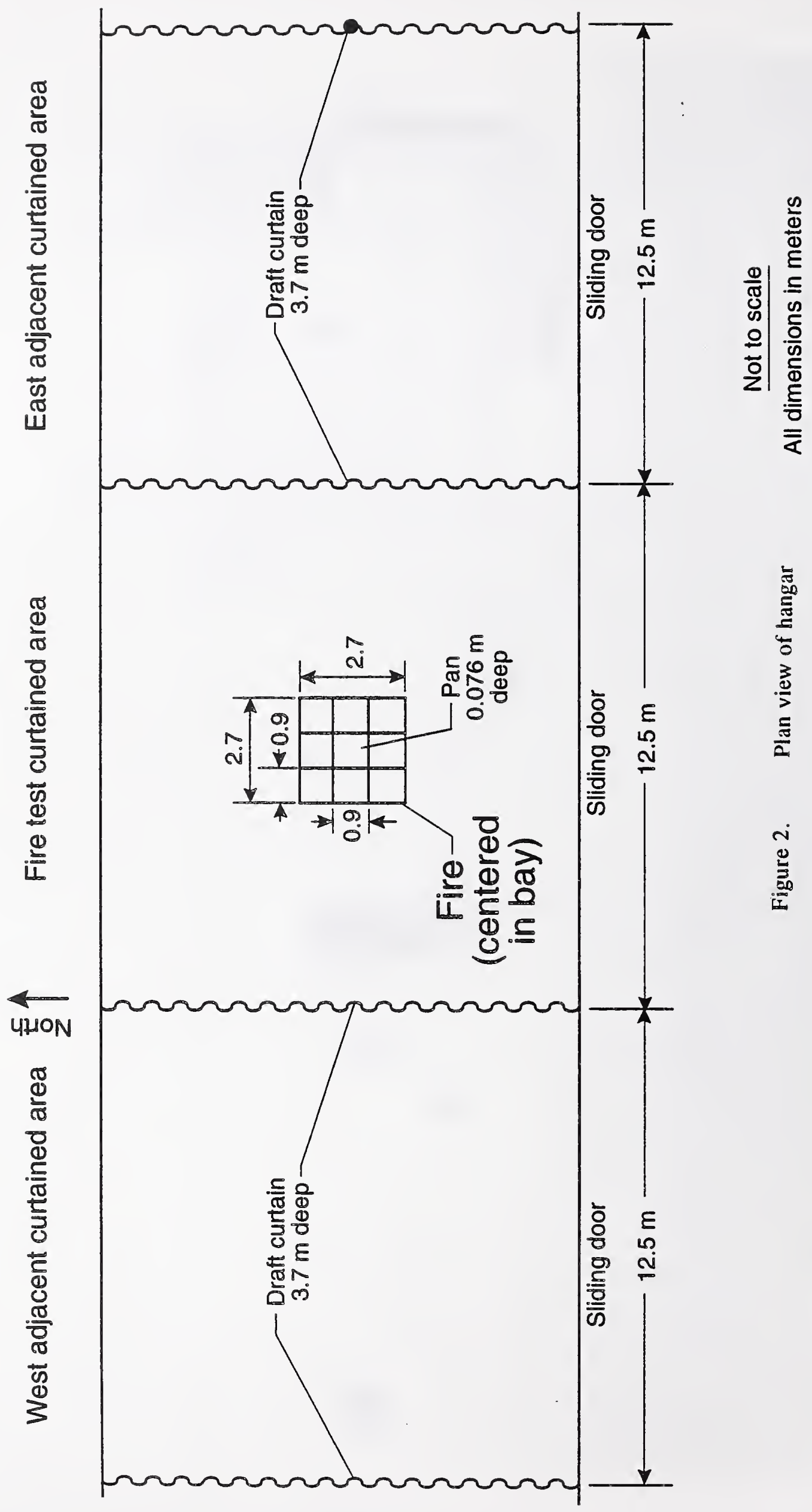




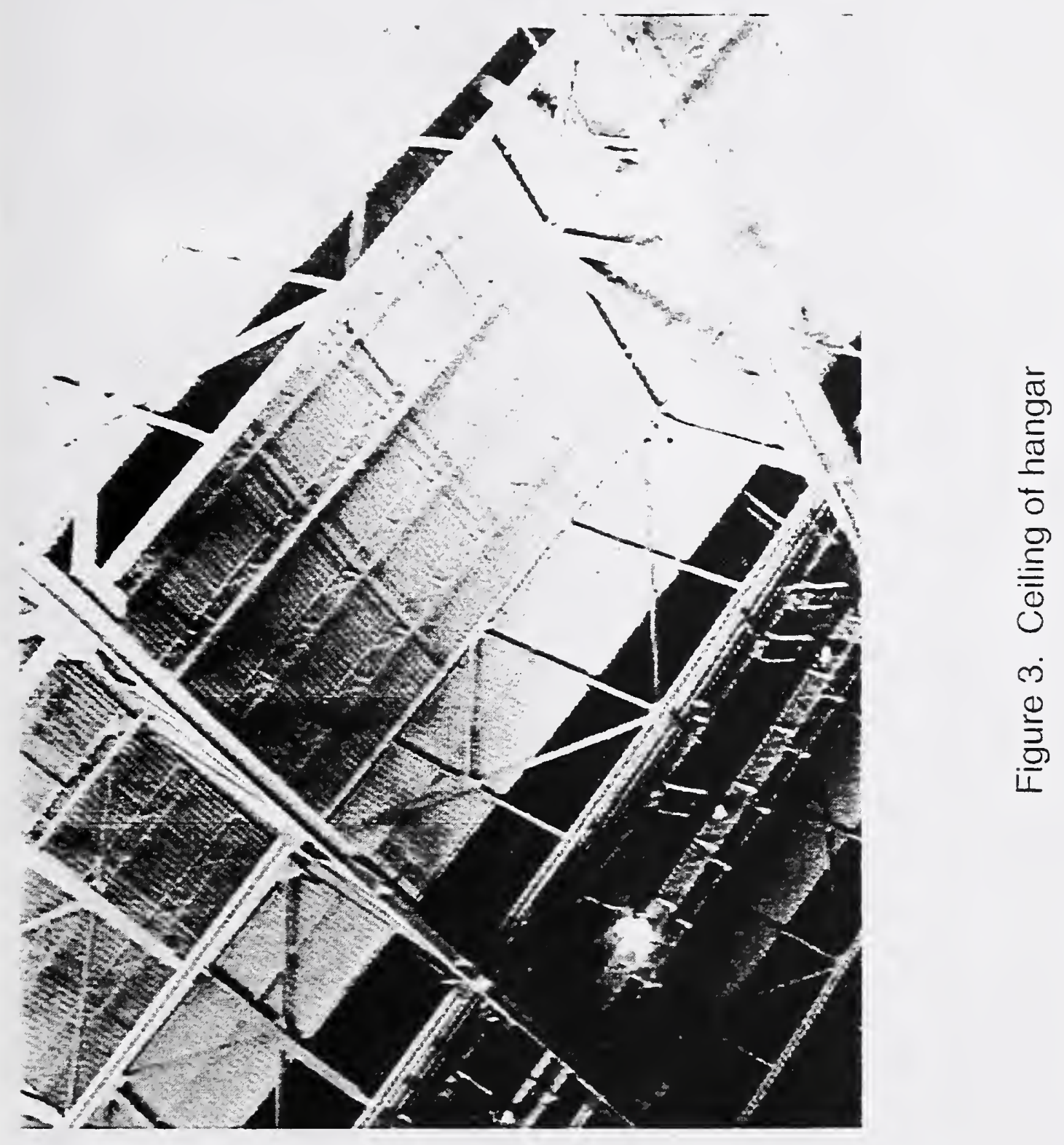




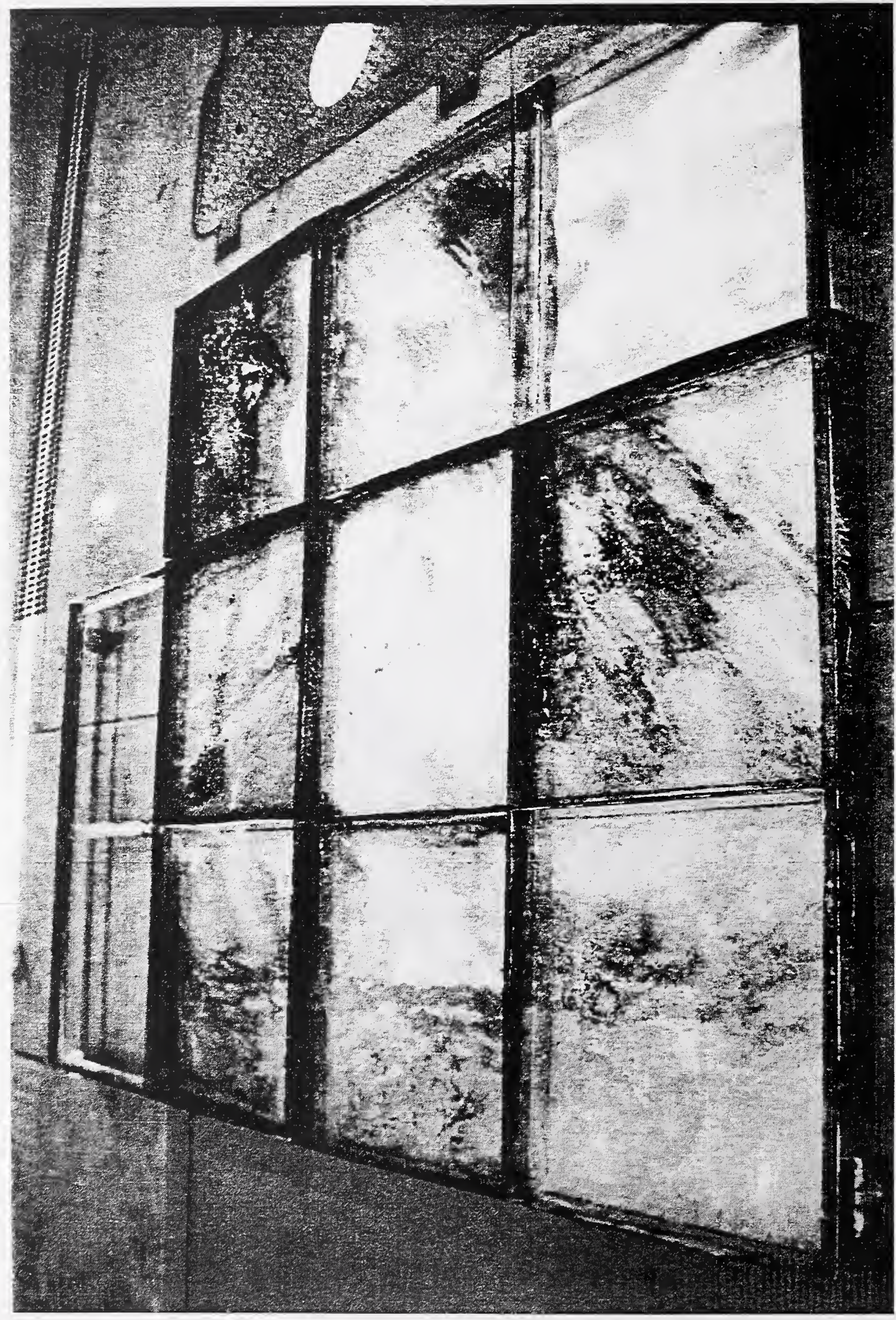




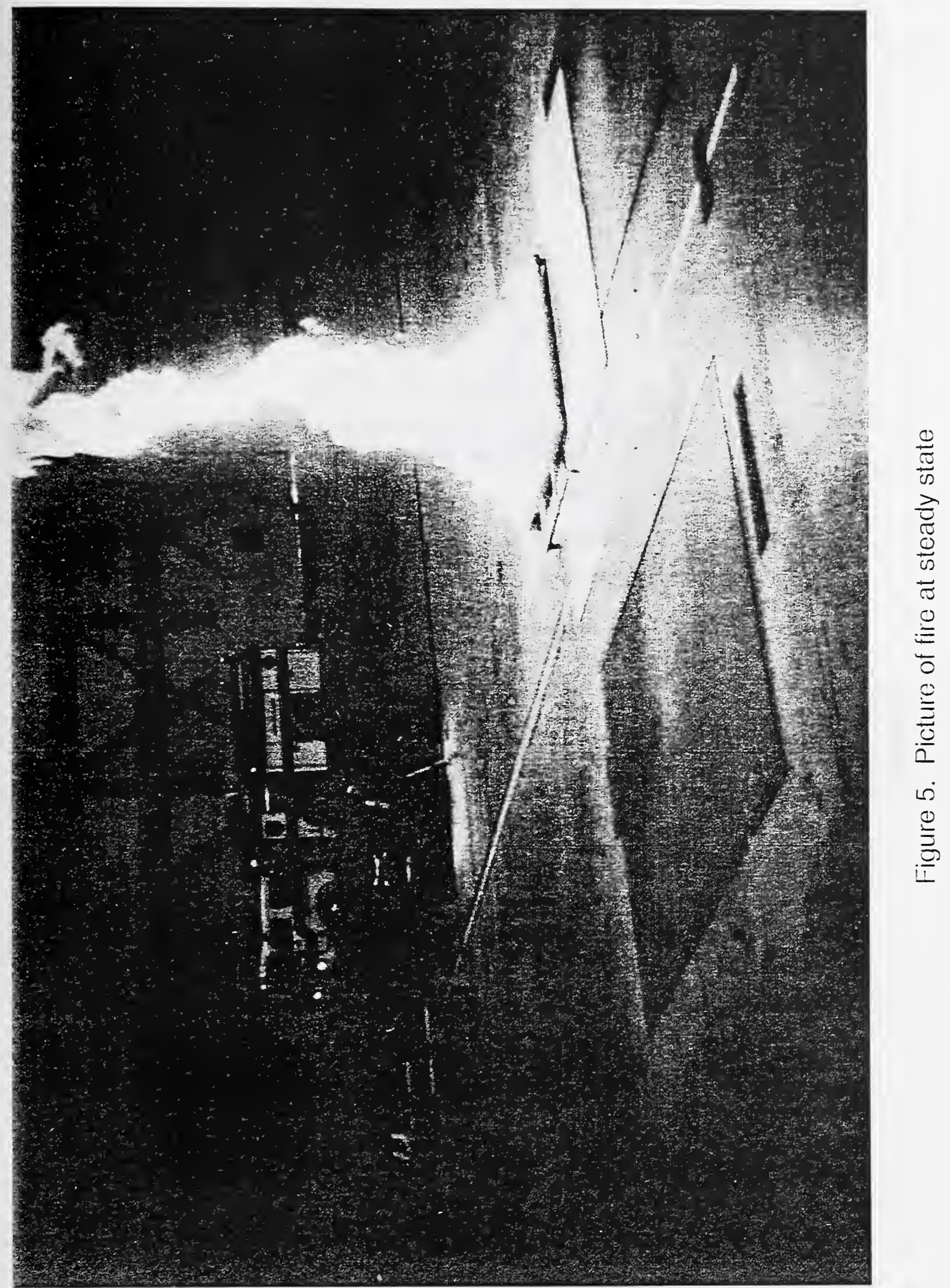




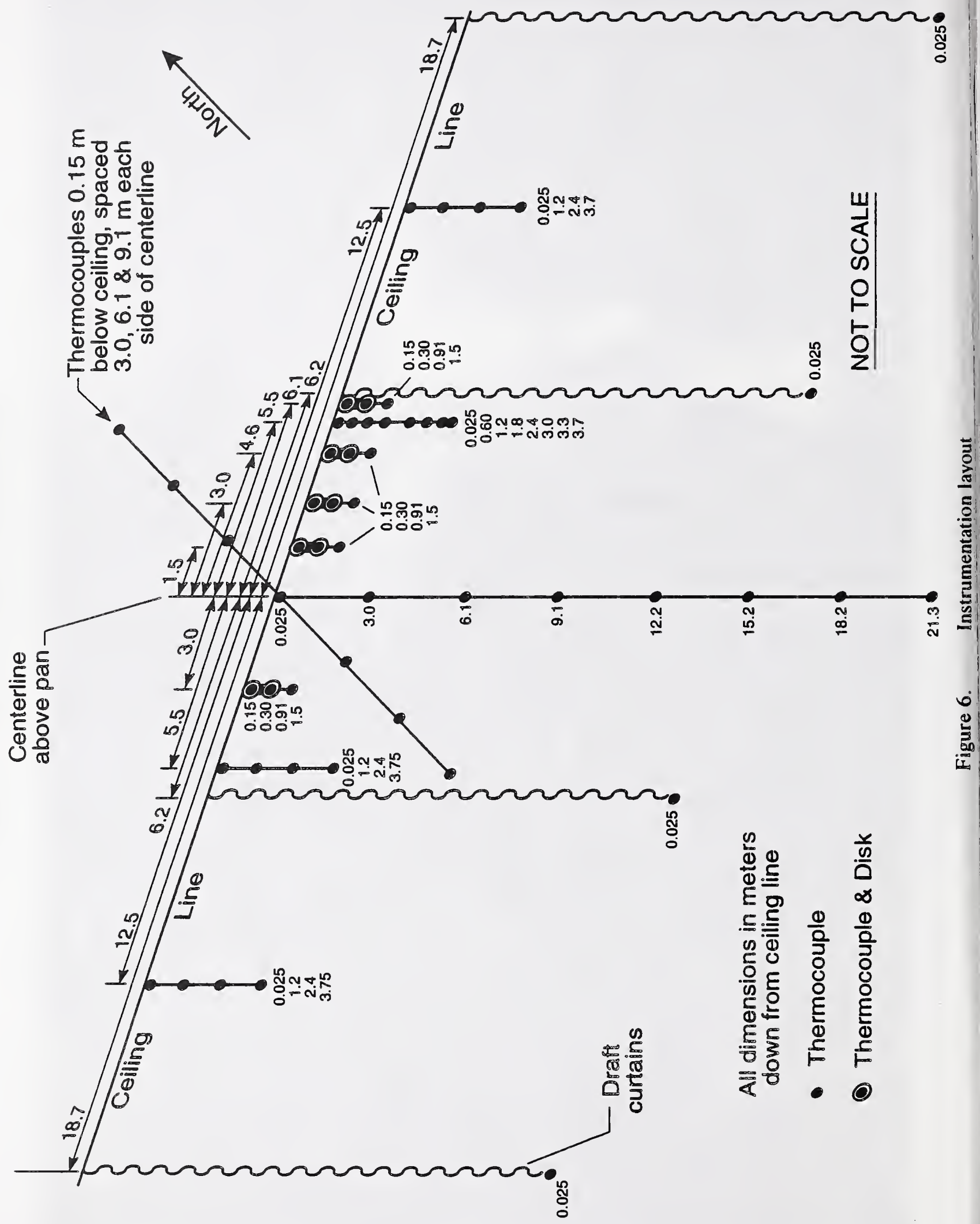




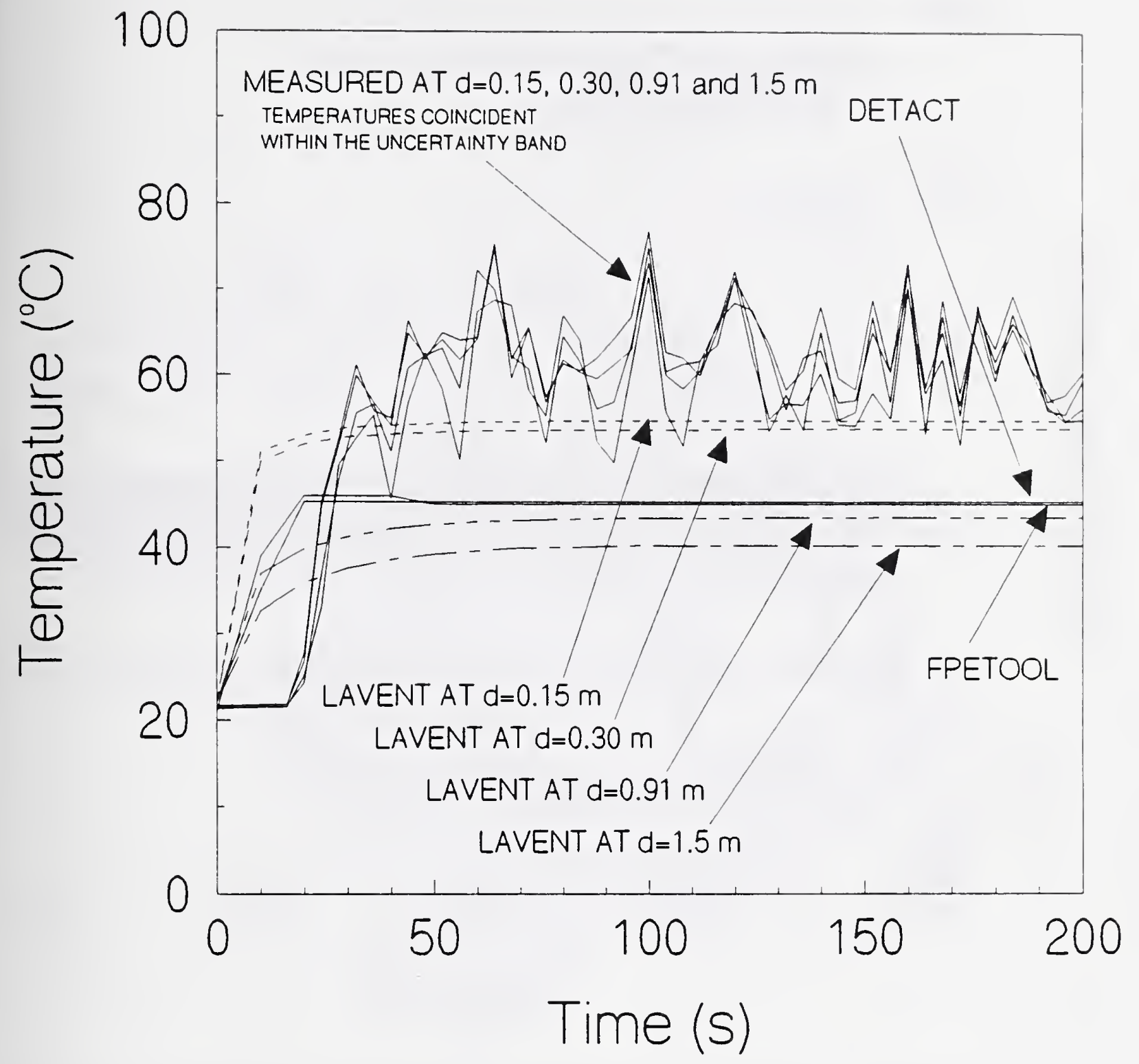

Figure 7. Measured vs. predicted gas temperatures at a radial distance of $1.5 \mathrm{~m}$ from the fire centerline, $\mathrm{r} / \mathrm{h}=0.05$. $\mathrm{d}=$ distance below the ceiling 


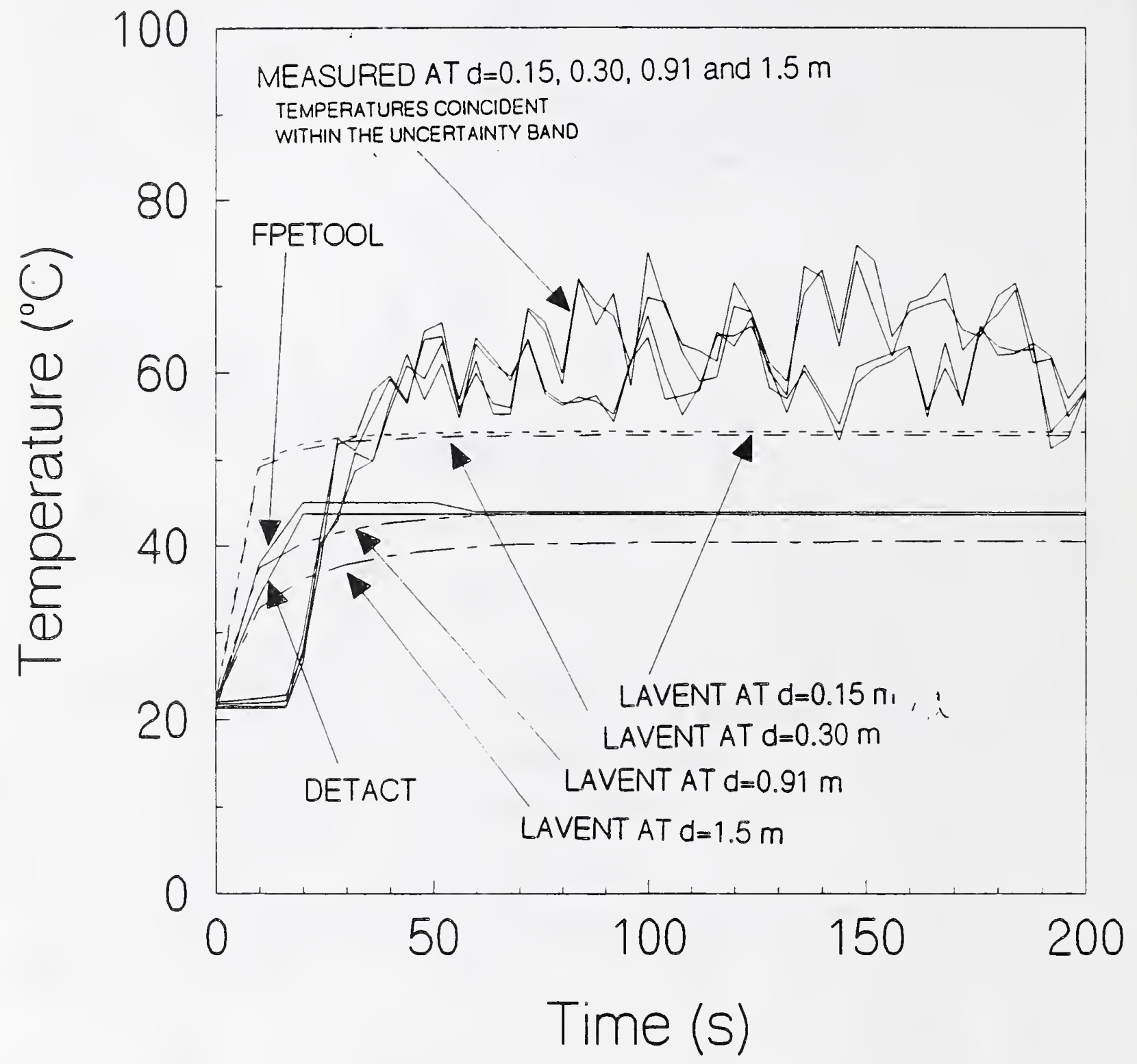

Figure 8. Measured vs. predicted gas temperatures at a radial distance of $6.1 \mathrm{~m}$ from the fire centerline, $\mathrm{r} / \mathrm{h}=0.20 . \mathrm{d}=$ distance below the ceiling 


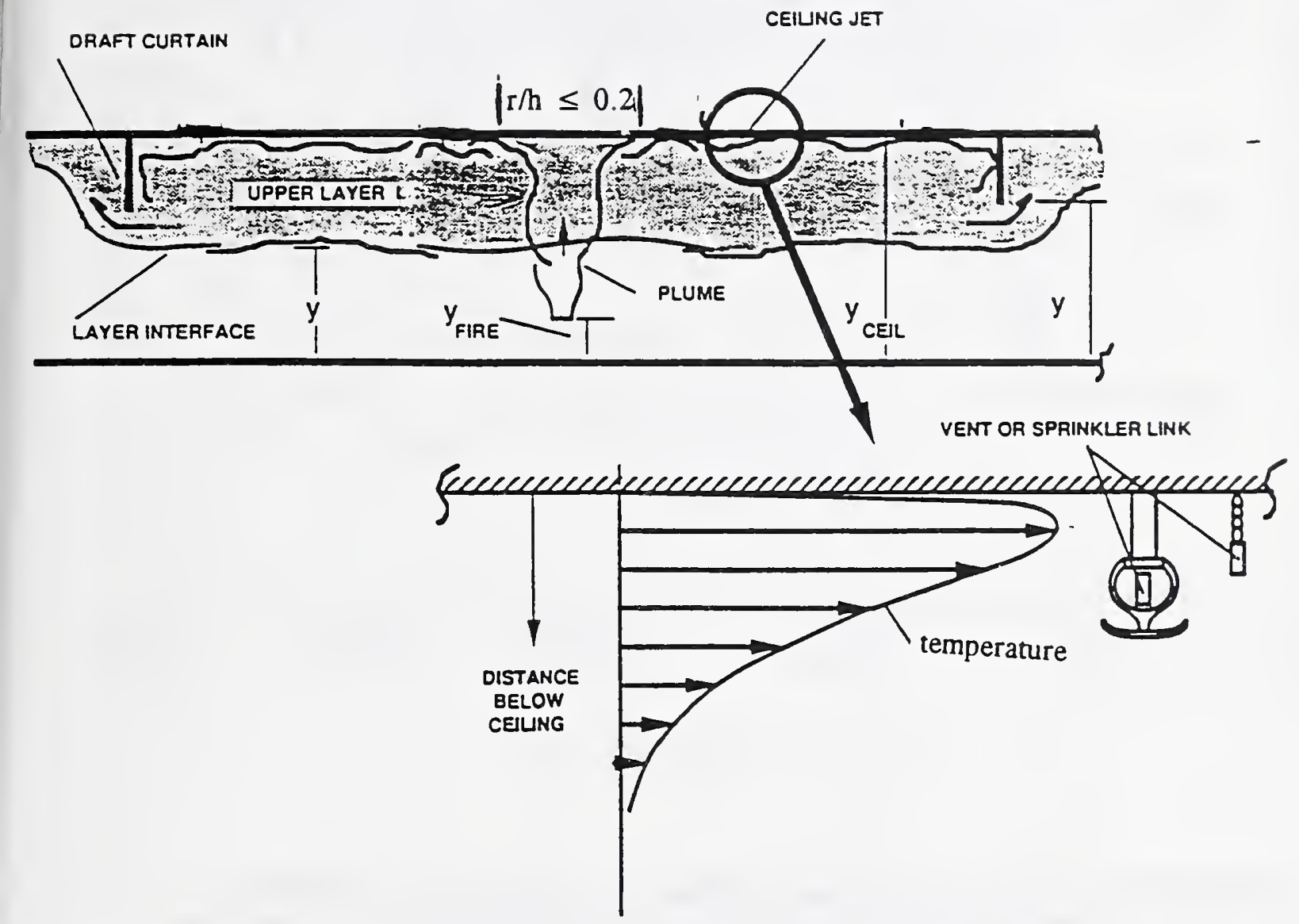

Figure 9. Illustration of plume and ceiling jet regions of a typical fire 


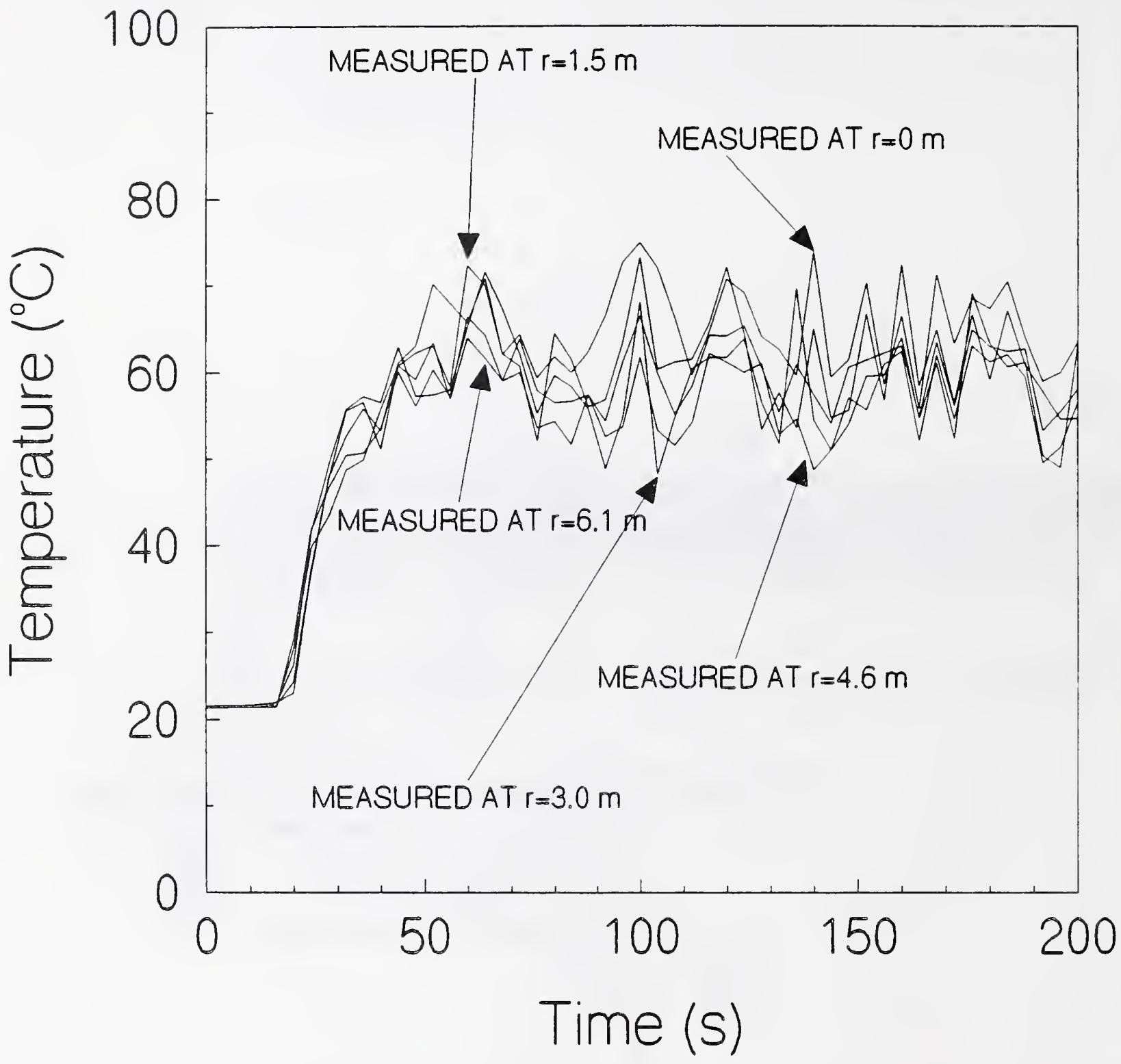

Figure 10. Temperature distribution within the plume measured at radial distances ( $\mathrm{r}$ ) of $0,1.5,3.0,4.6$, and $6.1 \mathrm{~m}$ from the fire centerline, $0.15 \mathrm{~m}$ below the ceiling. 


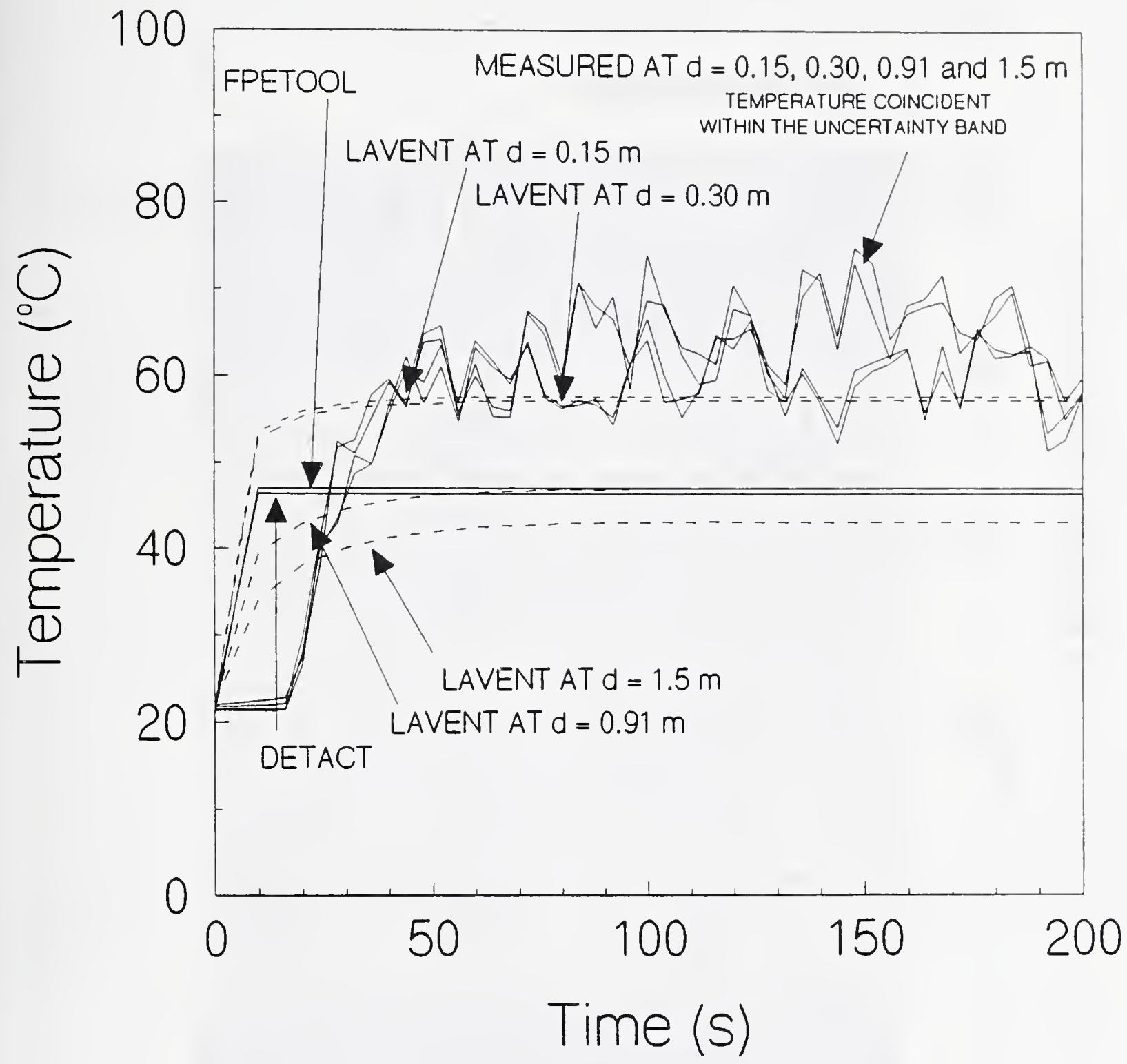

Figure 11. Measured vs. predicted gas temperatures at a radial distance of $6.1 \mathrm{~m}$ from fire centerline. Temperatures predicted using a 20 percent higher heat release rate of $9900 \mathrm{~kW}$ 


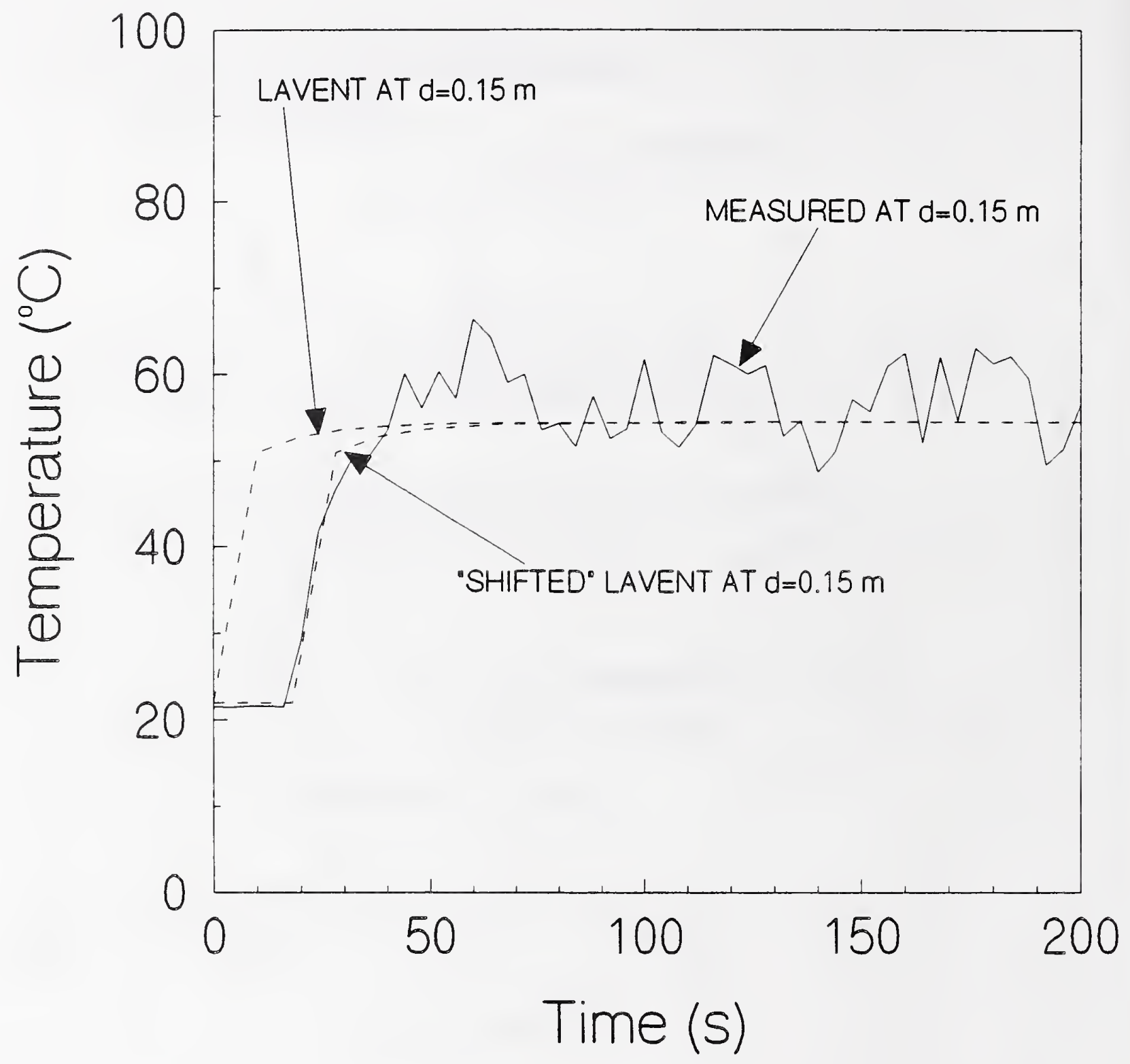

Figure 12. Temperature at $4.6 \mathrm{~m}$ radial distance from fire centerline with time shift, $r / h=0.15 d=$ distance below the ceiling 


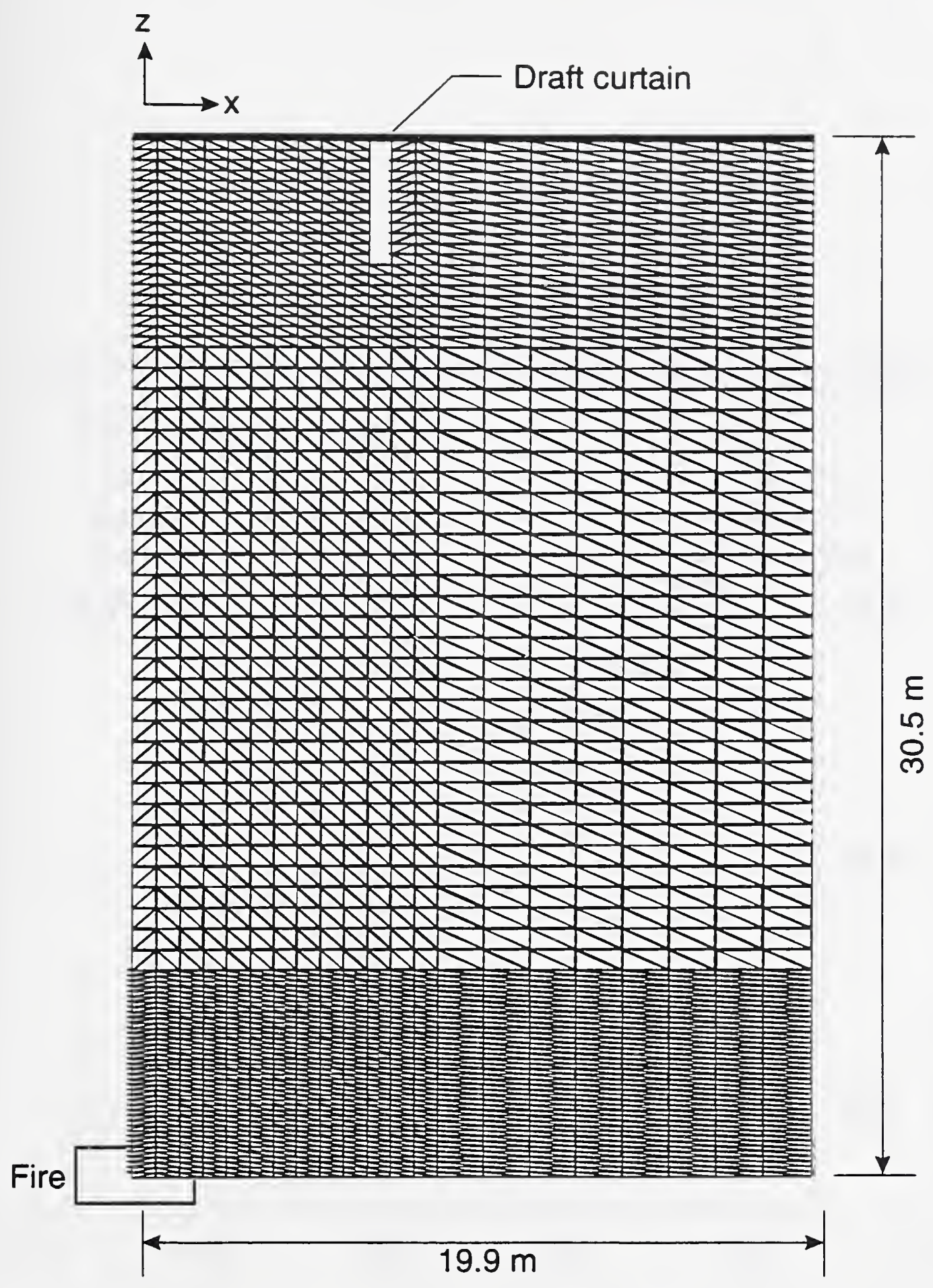

Figure 13. Two dimensional section of a three dimensional grid used for the CFD calculations representing a portion of the fire test curtained area and the east adjacent curtained area 


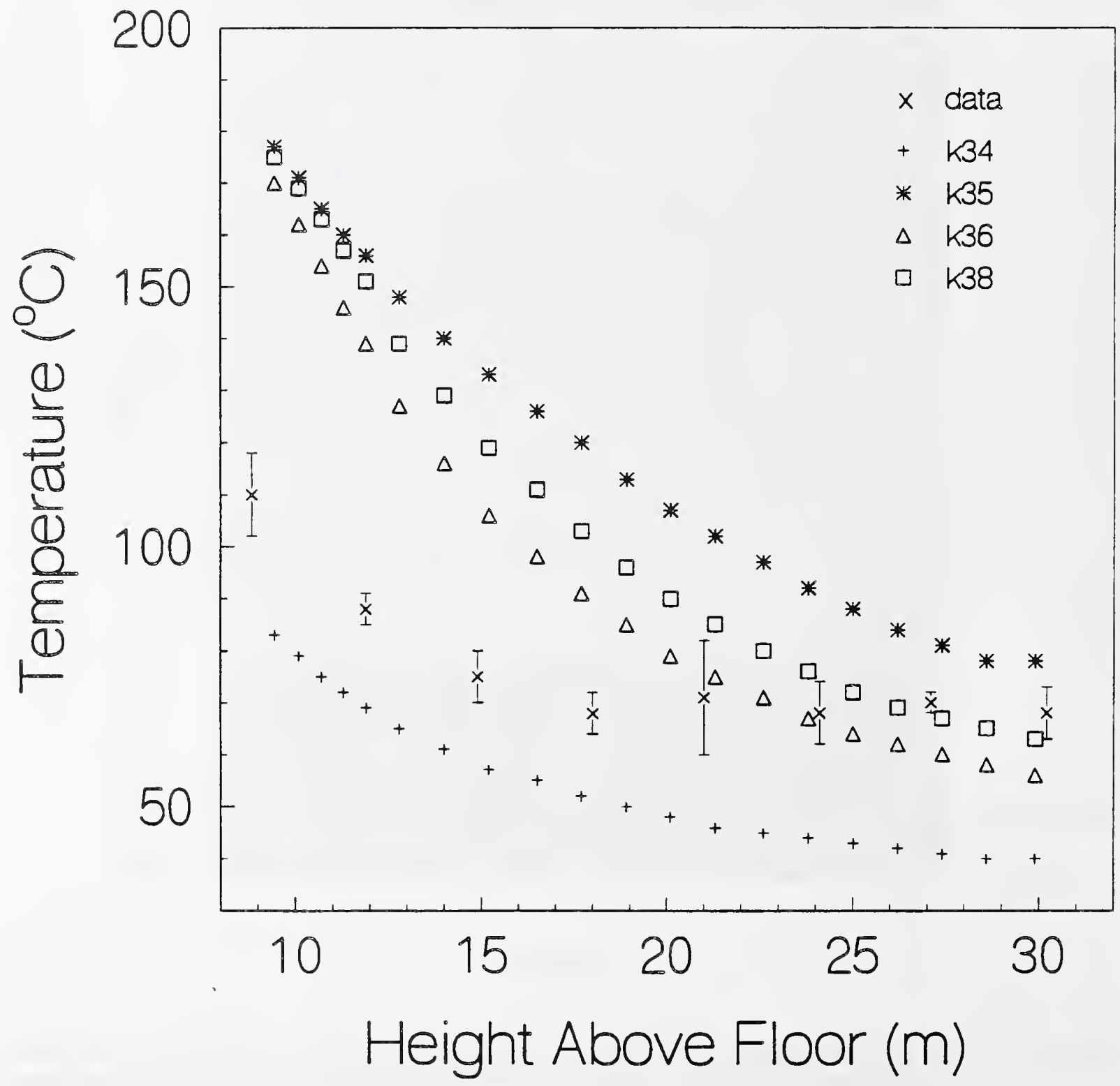

Figure 14. Comparison of CFD calculations using four different sets of $k-\epsilon$ constants to the measured plume centerline temperatures 


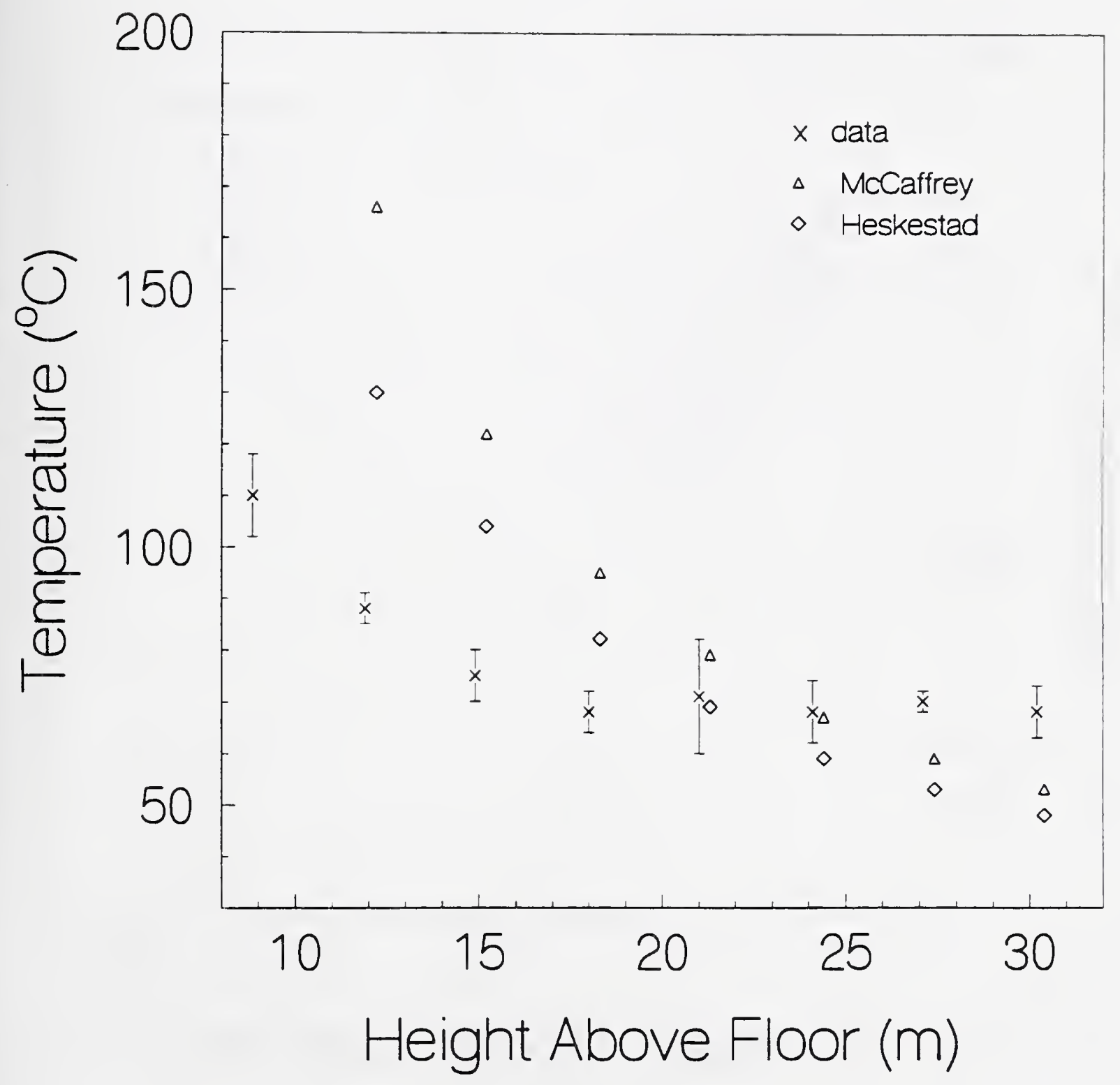

Figure 15. Comparison of the Heskestad and McCaffrey plume correlations to the measured plume centerline temperatures 


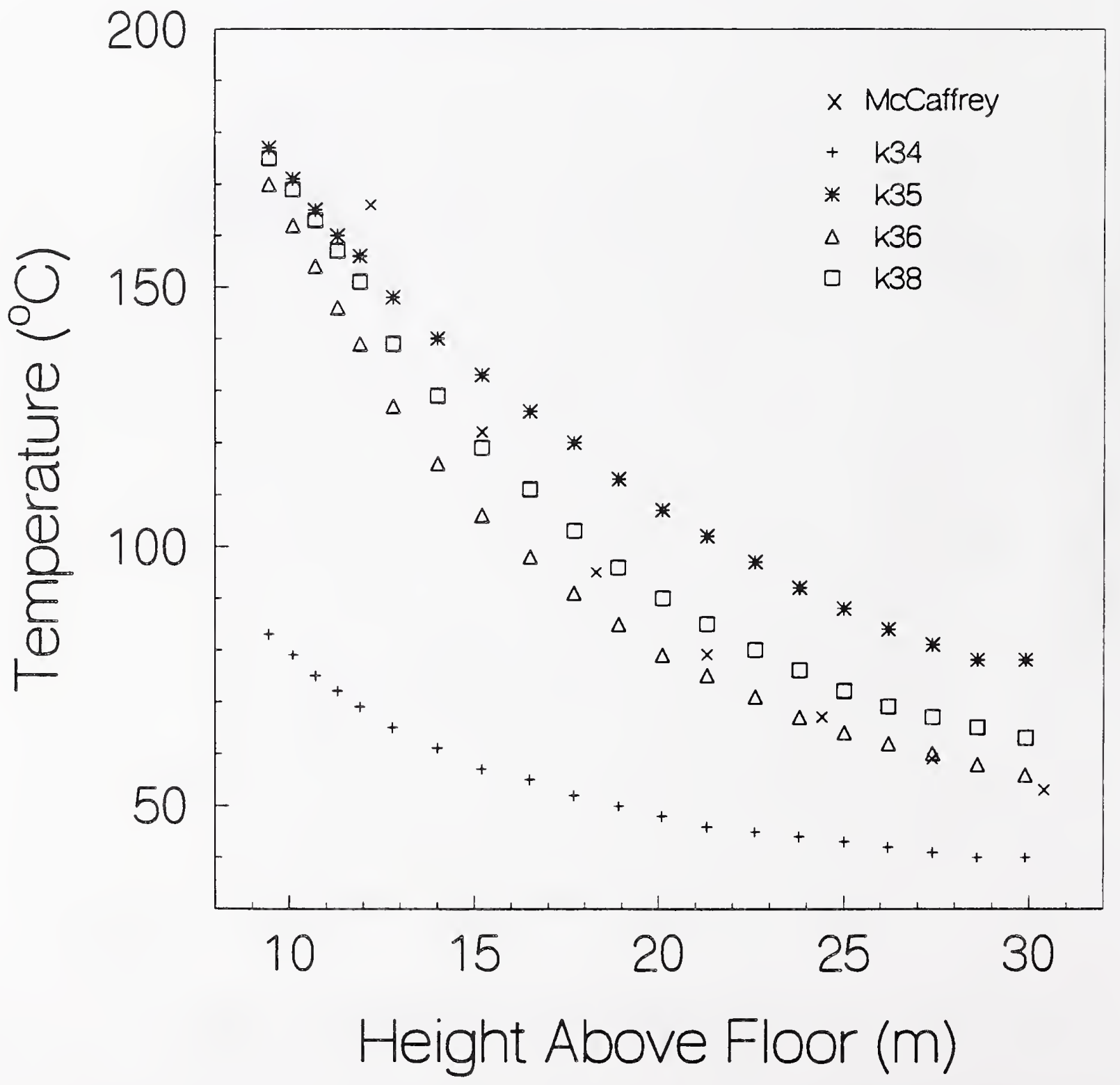

Figure 16. Comparison of calculations using four different sets of $k-\epsilon$ constants to the plume correlation of McCaffrey 


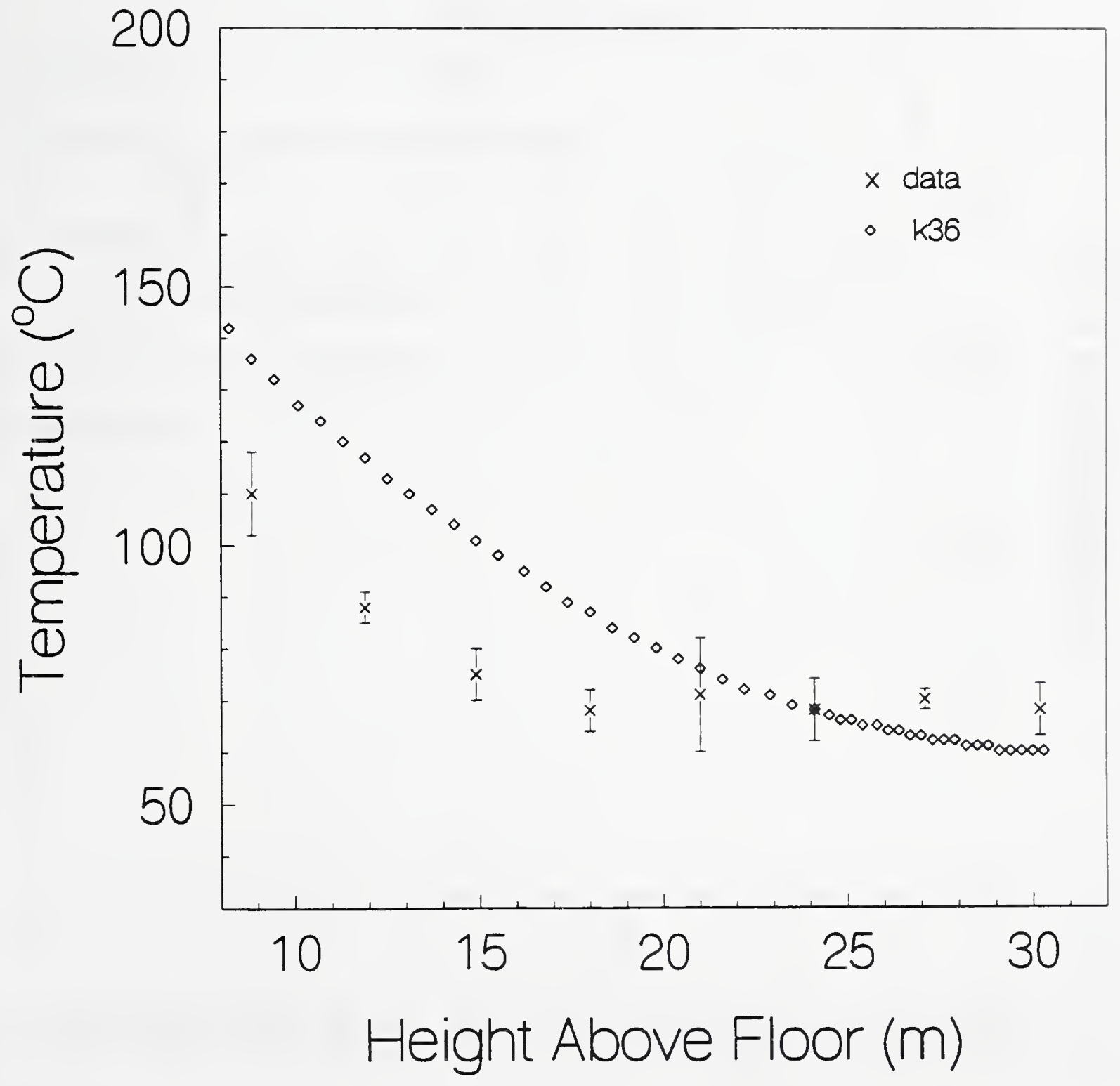

Figure 17. Comparison of a CFD calculation using the turbulence constants of $\mathrm{k} 36$ and a more detailed grid with the measured plume centerline temperatures 


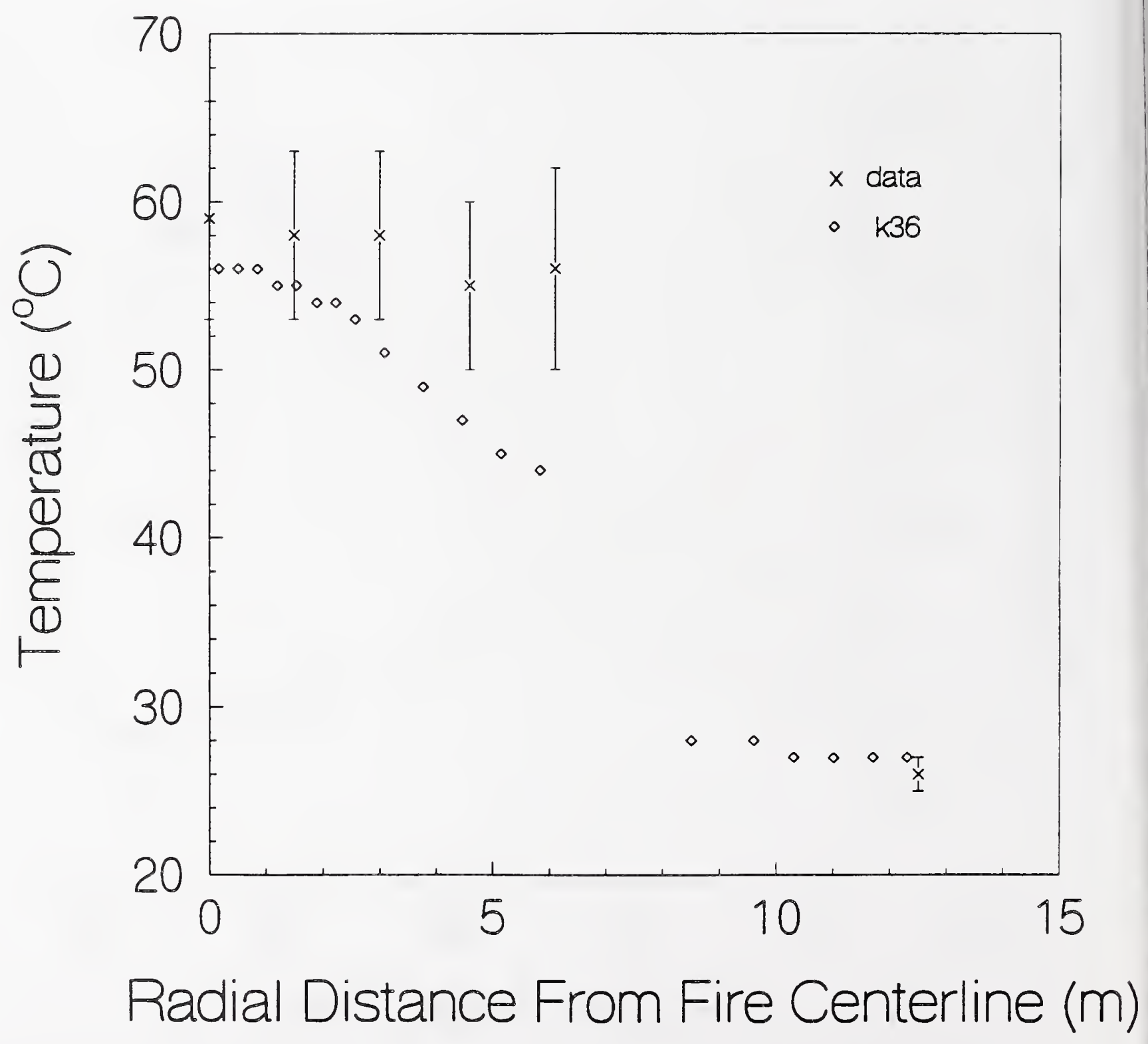

Figure 18. Comparison of the CFD calculated ceiling temperatures using a detailed grid and the $\mathrm{k} 36$ turbulence constants to the measured temperatures at various radial distances from the fire centerline and $0.15 \mathrm{~m}$ below the ceiling. 


\section{THE USE OF COMPUTER MODELS TO PREDICT TEMPERATURE}

AND SMOKE MOVEMENT IN HIGH BAY SPACES

SECTION B: MODELING OF THE HOT GAS MOVEMENT IN A NASA HIGH BAY CLEAN ROOM USING A COMPUTATIONAL FLUID DYNAMICS MODEL

William D. Davis and Kathy A. Notarianni

\section{SECTION CONTENTS}

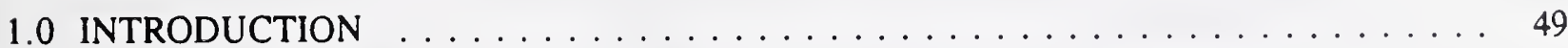

2.0 NASA GODDARD HIGH BAY CLEAN ROOM $\ldots \ldots \ldots \ldots \ldots \ldots \ldots \ldots \ldots$

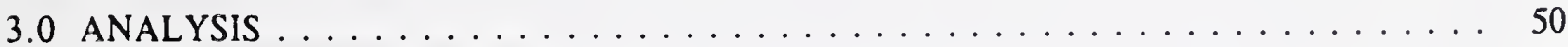

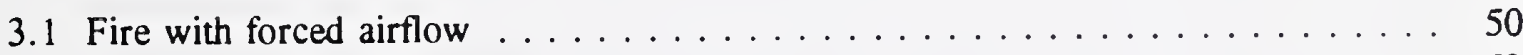

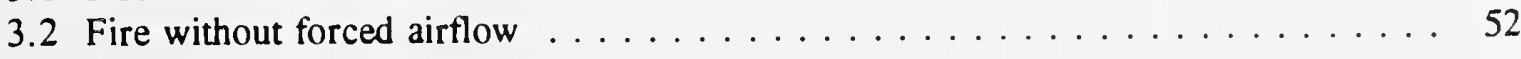

4.0 RESULTS AND CONCLUSIONS $\ldots \ldots \ldots \ldots \ldots \ldots \ldots \ldots \ldots \ldots \ldots$

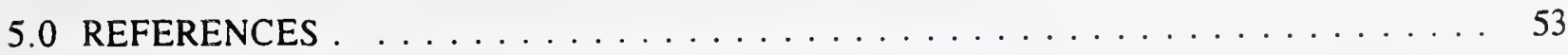




\section{LIST OF FIGURES}

Figure 1. Vertical slice of a typical grid used for the NASA clean room calculation ...

Figure 2. Temperature contours on a vertical plane through the fire for the $32 \mathrm{MW}$ fire

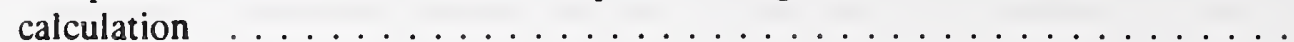

Figure 3. Temperature contours on a vertical plane through the fire for the $400 \mathrm{~kW}$ fire

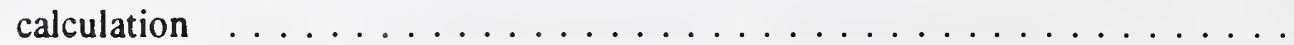

Figure 4. Temperature contours on a vertical plane through the fire for the $40 \mathrm{~kW}$ fire

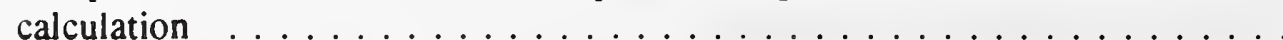

Figure 5. Temperature contours on a horizontal plane centered on the grid directly above

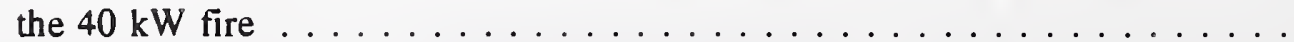

Figure 6. Temperature contours on a vertical plane through the fire at $50 \mathrm{~s}$ after ignition for a $400 \mathrm{~kW}$ fire $\ldots \ldots \ldots \ldots \ldots \ldots \ldots \ldots \ldots \ldots$

Figure 7. Temperature contours on a vertical plane through the fire at $100 \mathrm{~s}$ after ignition for a $400 \mathrm{~kW}$ fire .......................... . 


\subsection{INTRODUCTION}

NASA has numerous large, high bay spaces that are used to perform a variety of different functions. Many of these functions are critical to NASA operations. Examples of high bay spaces at NASA include those used for clean rooms, shuttle simulators, assembly/storage, vacuum and vibration chambers, vehicle assembly, and/or testing facilities with payloads. These spaces represent some of the most difficult fire protection challenges in that detection of a fire in a large space may be delayed due to the distance smoke and products of combustion must travel to reach the detector, the large amount of ambient air for smoke dilution, the high dollar value of these spaces and the low damage threshold of a clean room. Some of these spaces also involve forced airflow.

As was shown in section $A$ of this report, current computer fire models do not provide accurate temperature predictions in a high bay space where the region of interest is within the plume. Design for fire protection in these spaces at present relies upon "best estimate" guess work. Therefore, it is important for NASA to develop a methodology by which to determine fire protection options for these spaces. The methodology must be in a suitable form to be incorporated into the NASA fire protection manual and be easily usable by the field engineers. This project represents the first step toward developing such a methodology. An existing NASA high bay space was modelled using a field model to determine how the existing fire detection devices would respond to various size fires in the space.

The CFD model, HARWELL FLOW3D [1], used to model the NASA high bay space has already been successfully applied to the analysis of fire problems in both forced and unforced flow situations at NIST. Compartment fires with single and three room configurations were successfully modeled [2] as part of a validation project. section $A$ of this report extended the validation efforts to high bay spaces. The model was used to successfully simulate an experiment [3] used to determine the impact on the ceiling jet flow of beams on a flat ceiling. Finally, the model has been used to analyze and solve a fire problem associated with the Navy's 19F4 Fire Fighting Trainer where winds blowing in from the ocean adversely impacted the operation of the trainer [4].

A clean room at Goddard Space Flight Center in Greenbelt, MD, was chosen to be analyzed for detector placement based on the premise that the forced air flow through the room presented the possibility of adversely effecting the detection of smoke from a fire. Because of the air flow in the room, models such as DETACT-QS, FPETOOL, and LAVENT [5-7] used for the earlier analysis are not appropriate for use in this space. These computer fire models assume that the plumes are axisymmetric, neglect flow velocities in both the upper and lower layers and make the assumption that an upper layer is formed regardless of fire size and flow conditions. The air flow in this clean room may have sufficient velocity to negate all of these assumptions for small fires. The purpose of this analysis will be to study the impact of fire size on the distribution of hot gas and detector activation in the clean room.

\subsection{NASA GODDARD HIGH BAY CLEAN ROOM}

The Goddard clean room is the largest known laminar flow clean room in the world. The space measures $38.1 \times 30.5 \times 27.4$ meters $(125 \times 100 \times 90 \mathrm{ft})$ in dimension. The room is rated as a class 10 clean room and is large enough to accommodate two full size shuttle payloads simultaneously. Two decks are located on the side of the room opposite the air intake wall. Two 35 ton cranes with hook heights of 21 and $24.4 \mathrm{~m}(69$ and $80 \mathrm{ft})$ are mounted on beams near the ceiling. HEPA filters are used to remove particulate matter at the air intake wall. A perforated return air grille is used for 
the outlet wall which is located opposite the intake wall. The laminar air flow in the room is uniform from floor to ceiling in a horizontal direction and is maintained at a rate of $0.508 \mathrm{~m} / \mathrm{s}(1.67 \mathrm{ft} / \mathrm{s})$ by a computer operated mechanical control system. The concrete floor is covered by a polyurethene coating. The clean room is used for assembly and testing of space flight hardware.

A diagram of the room showing the gridding is given in figure 1. The solid decks are shown as rectangles extending out from the right side of the grid. The cranes are approximated by the two squares inserted in the upper right portion of the grid. Figure 1 represents one vertical plane extending from the floor to the ceiling of the clean room. The grid is actually a three dimensional grid of size $25 \times 20 \times 24$. The large grid volumes are cubic with each side having a length of 1.524 $\mathrm{m}(5 \mathrm{ft})$ and the smaller grid volumes have a vertical length of $0.762 \mathrm{~m}(2.5 \mathrm{ft})$ with a square base of $1.524 \mathrm{~m}(5 \mathrm{ft})$ on a side.

The smoke detectors on the outlet wall are spaced every $3.66 \mathrm{~m}(12 \mathrm{ft})$ in both the horizontal and vertical direction. Since the two decks essentially compartmentalize the outlet wall into three spaces, the initial detector design required the placement of at least one row of detectors in each space. There are no detectors on the ceiling.

\subsection{ANALYSIS}

\subsection{FIRE WITH FORCED AIRFLOW}

Smoke flow from a fire will be affected by both the fire size, which will impact buoyancy, and the forced airflow in the room. Large fires, which will create strong buoyant forces, should produce a plume which will propel most of the smoke toward the ceiling and form a ceiling layer. Small fires will have weak buoyant forces which may result in very little upward movement before the ambient air flow causes the smoke to exit the room. The horizontal smoke spread perpendicular to the flow velocity, may be reduced with a small fire, hence detector spacing for small fires may be more critical than for large fires.

In the model, the fire was placed three grids off of the floor and in the far center of the room near the inlet wall. The location of the fire off the floor was suggested by the raised assembly areas which were in active use when the clean room was visited. The fire was modelled by uniformly distributing the heat release rate in four adjacent grid volumes. Due to the geometrical simplicity of the room, it was felt that varying the location of the fire was not necessary. The default values for the $k-\epsilon$ turbulence model were used in these calculations.

The model calculations give the location of the heated gas but do not explicitly track smoke particles. A connection between the calculated hot gas distribution and the smoke distribution is therefore required in order to use the hot gas distribution to track the smoke particles. It is assumed in this analysis that the smoke distribution is coincident with the distribution of hot gas. This assumption is supported by the experiments of Heskestad and Delichatsios [8] which showed that for a fire under a flat smooth ceiling, the optical density (smoke density) is correlated with the local rise in temperature. While there was no forced airflow present in these experiments, the smoke did follow the gas flow produced by the buoyant force of the fire. Unless there is substantial deposition of smoke it would be expected that in forced flow situations, the smoke would again follow the gas flow and that the smoke density would correlate with the local temperature rise. Therefore, for the analysis used here, it was assumed that the excess temperature plots were sufficient to locate the smoke particles. 
Three fire sizes, $32 \mathrm{MW}, 400 \mathrm{~kW}$, and $40 \mathrm{~kW}(30000 \mathrm{Btu} / \mathrm{s}, 380 \mathrm{Btu} / \mathrm{s}, 38 \mathrm{Btu} / \mathrm{s})$ were used to investigate the impact of fire size on detectability. The $32 \mathrm{MW}(30000 \mathrm{Btu} / \mathrm{s})$ fire was chosen as it represents the maximum heat release rate for the default fire in the model, LAVENT. The other fire sizes represent smaller, more likely fires for the clean room with the $40 \mathrm{~kW}$ (38 Btu/s) fire approximating the size fire found in a wastepaper basket. Contour plots, in a vertical plane passing through the fire, of excess temperature (temperature above ambient) are given in figures 2,3 , and 4 for the three fires. The darker shaded areas represent higher temperature areas which should contain higher smoke concentrations. Clear white areas will contain no smoke. The small values for the excess temperatures are due to the large grid volumes used to model these very small fires in this large space.

From the figures, it can be seen that the larger two fires produce sufficient buoyancy to allow the heated gas to reach the ceiling and hence may be detected by at least some of the wall mounted detectors near the ceiling. For the largest of the fires, there is potential for plume driven circulation patterns to set up where some of the smoke detectors at lower elevations may not detect the fire.

The small fire did not possess enough buoyancy for the fire plume to rise to the ceiling by the time the heated gas exited the room via the outlet vents. Hence, the detection of a small fire in this space will require wall mounted detectors which are approximately at the height of the fire. The spread of the heated gas in the horizontal direction at the base of the fire is shown in figure 5. There appears to be adequate horizontal spread for the smoke to encounter at least two smoke detectors.

The computer fire models used in section A assume that the fire plume rises vertically to the ceiling. The forced ventilation effects on the fire plume predicted by the CFD calculations for small fires would not be predicted by these fire models.

While the distribution of the smoke detectors may be adequate, the question still remains concerning whether the sensitivity of the detectors are adequate for small fires. The wall-mounted detectors in the clean room are photoelectric smoke detectors which have a rating of $5.2-8.1$ percent obscuration per meter $(1.9-4.8$ percent obscuration per foot). This rating is related to the optical density per meter of the smoke by [9]

$$
I_{2} / I_{o \alpha}=10^{-D L}
$$

Where $I_{\lambda}$ is the observed intensity, $I_{o \lambda}$ is the incident intensity, $D$ is the optical density per meter, and $\mathrm{L}$ is the path length. $\mathrm{D}$ is related to the fire by the relation

$$
D=D_{m}\left(\Delta m / V_{c}\right)
$$

Where $D_{m}$ is the mass optical density, $\Delta m$ is the mass consumed in the fire, and $V_{c}$ is the smoke volume.

The above two equations must be evaluated for a given fire in order to estimate the optical density at the detectors. The values of $D_{m}$ and $\Delta m$ depend on the fuel and also on the heat release rate. Fuels typically have heats of combustion between 16 and $40 \mathrm{~kJ} / \mathrm{g}$ and produce mass optical densities between 0.12 and $1.4 \mathrm{~m}^{2} / \mathrm{g}\left(590\right.$ and $\left.6800 \mathrm{ft}^{2} / \mathrm{lb}\right)$. Fuels found in the clean room may consist of 
plastics, mylars, metal, and wood. For the calculations given below, it will be assumed that the material heat of combustion will be $30 \mathrm{~kJ} / \mathrm{g}(28000 \mathrm{Btu} / \mathrm{lb})$ and the mass optical density produced will be $0.5 \mathrm{~m}^{2} / \mathrm{g}\left(2400 \mathrm{ft}^{2} / \mathrm{lb}\right)$. This will give a middle range result with some materials producing more smoke and others less smoke. The smoke mass per volume $\Delta \mathrm{m} / \mathrm{V}_{\mathrm{c}}$ will be estimated using the following relation

$$
\frac{\Delta m}{V_{c}}=\frac{\dot{Q}}{H_{c} A v}
$$

where $\mathrm{H}_{\mathrm{c}}$ is the heat of combustion, $\mathrm{Q}$ is the heat release rate, $\mathrm{A}$ is the area occupied by the smoke perpendicular to the forced airflow, and $v$ is the velocity of the forced airflow in the clean room. The area $\mathrm{A}$ at the detector wall is determined from the field model calculations by assuming that the smoke is essentially contained in the region at the wall where the excess temperature is greater than $1 / 3$ of the maximum excess temperature.

The smoke from the $40 \mathrm{~kW}(38 \mathrm{Btu} / \mathrm{s})$ fire impacts an area on the outlet wall of approximately 140 $\mathrm{m}^{2}\left(1500 \mathrm{ft}^{2}\right)$, approximately $2 / 3$ of the area under the lower deck. Using the above mass optical density and heat release requires a detector with a rating of 2.3 percent obscuration per meter $(0.7$ percent per $\mathrm{ft}$ ) which is significantly below the sensitivity of the existing detectors. The $400 \mathrm{~kW}$ ( 380 $\mathrm{Btu} / \mathrm{s})$ and $32 \mathrm{MW}(30000 \mathrm{Btu} / \mathrm{s})$ fires had perpendicular areas which approximately equaled the clean room wall, $840 \mathrm{~m}^{2}\left(9000 \mathrm{ft}^{2}\right)$. The $400 \mathrm{~kW}(380 \mathrm{Btu} / \mathrm{s})$ fire would require a rating of 3.9 percent per meter ( 1.2 percent per $\mathrm{ft}$ ) or 75 percent of the existing detector rating while the $32 \mathrm{MW}$ fire required a rating of 200 percent obscuration per meter (61 percent per $\mathrm{ft}$ ).

Both the $40 \mathrm{~kW}(38 \mathrm{Btu} / \mathrm{s})$ and the $400 \mathrm{~kW}(380 \mathrm{Btu} / \mathrm{s})$ fires generated estimated smoke concentrations below the detection limit of the existing smoke detectors in the clean room. This conclusion depends on the smoke following the heated gas and being well mixed.

\subsection{FIRE WITHOUT FORCED AIRFLOW}

The $400 \mathrm{~kW}(380 \mathrm{Btu} / \mathrm{s})$ fire was used to demonstrate how the analysis can change when the forced airflow is absent in the clean room. The heat source representing the fire was positioned as in the earlier analysis but a smaller grid was used to define the plume more accurately. Two openings, simulating open doors, centered at the floor on opposite walls are used to vent the room. Figures 6 and 7 present the calculated temperature distribution at times of 50 and $100 \mathrm{~s}$ after the fire ignition. As can be seen from the figures, a vertical plume rises from the fire source, is deflected by the ceiling and forms a ceiling jet along the ceiling. Since the fire is not symmetric in the room, the ceiling jet strikes the near wall first and sets up a circulation pattern there. The smoke is concentrated in the ceiling jet and does not diffuse as it does in the forced airflow environment. The gas temperature without forced airflow, see figures 3 and 6, is substantially higher than is calculated in the forced airflow simulation. In these situations, smoke detectors located at substantial distances beneath the ceiling would be of little use in the early detection of the fire. Because the smoke is concentrated in the ceiling jet, the requirements on smoke detector sensitivity near the ceiling would be less severe than in the forced airflow environment. 


\subsection{RESULTS AND CONCLUSIONS}

1. Computer fire models examined in section A of this report are inappropriate to use for detector analysis in forced air environments.

2. The design fire size is of extreme importance in structures where there is a forced air flow. For the NASA Goddard clean room, small fire plumes would not reach the ceiling, hence the distribution and sensitivity of side wall detectors becomes important.

3. Large fires in structures containing forced air flow may provide sufficient buoyancy for the fire plume to reach the ceiling. In these situations, wall mounted detectors may be shielded by obstructions from the smoke and not detect the fire.

4. Detector sensitivity in the NASA Goddard clean room should be increased for small fire detection.

\subsection{REFERENCES}

1. FLOW3D Release 2.3: USER MANUAL, CFD department, AEA Industrial Technology, Harwell Laboratory, United Kingdom, July, 1990.

2. Davis, William D., Forney, Glenn P., and Klote, John H., Field Modeling of Room Fires. NISTIR 4673, 1991.

3. Forney, Glenn P., Davis, William D., and Klote, John H., Simulating the Effect of Beamed Ceilings on Smoke Flow, Part I. Comparison of Numerical and Experimental Results. NISTIR 4994, 1992.

4. Forney, Glenn P. and Davis William D., Analyzing Strategies for Eliminating Flame Blow-down Occurring in the Navy's 19F4 Fire Fighting Trainer. NISTIR 4825, 1992.

5. Stroup, D. W., Evans, D.D., and Martin, P.M., Evaluating Thermal Fire Detection Systems, NBS SP 712, National Bureau of Standards, Gaithersburg, MD, 1986.

6. Nelson, H.E., FPETOOL: Fire Protection Engineering Tools for Hazard Estimation, NISTIR 4380, National Institute of Standards and Technology, Gaithersburg, MD 1990.

7. Davis, W.D., and Cooper, L.Y., Estimating the Environment and the Response of Sprinkler Links in Compartment Fires With Draft Curtains and Fusible Link-Actuated Ceiling Vents. Part 2. User Guide for the Computer Code LAVENT., NISTIR 89-4122, National Institute of Standards and Technology, Gaithersburg, MD, 1989.

8. Heskestad, G, and Delichatsios, M. A., Environments of Fire Detectors - Phase II: Effect of Ceiling Configuration. Volume I. Measurements. NBS-GCR-78-128, 1978. p. 1

9. Mulholland, George W., Smoke Production and Properties. In: DiNenno, P. J. ed, SFPE Handhook of Fire Protection Engineering, Society of Fire Protection Engineering, Boston, MA, First ED., 1988. p. 368-376. 


\section{ACKNOWLEDGMENTS}

This study was funded by the U.S. General Services Administration (GSA) and the National Aeronautics and Space Administration (NASA). Mr. Daniel Madrzykowski and Mr. Jay McElory of NIST assisted with the live fire tests. Special thanks to Mr. Dave Burkhart for obtaining permission for NIST to take measurements in the hangar, and to David Stroup of GSA and Phillip Tapper of NASA, who served as the project liaisons. 


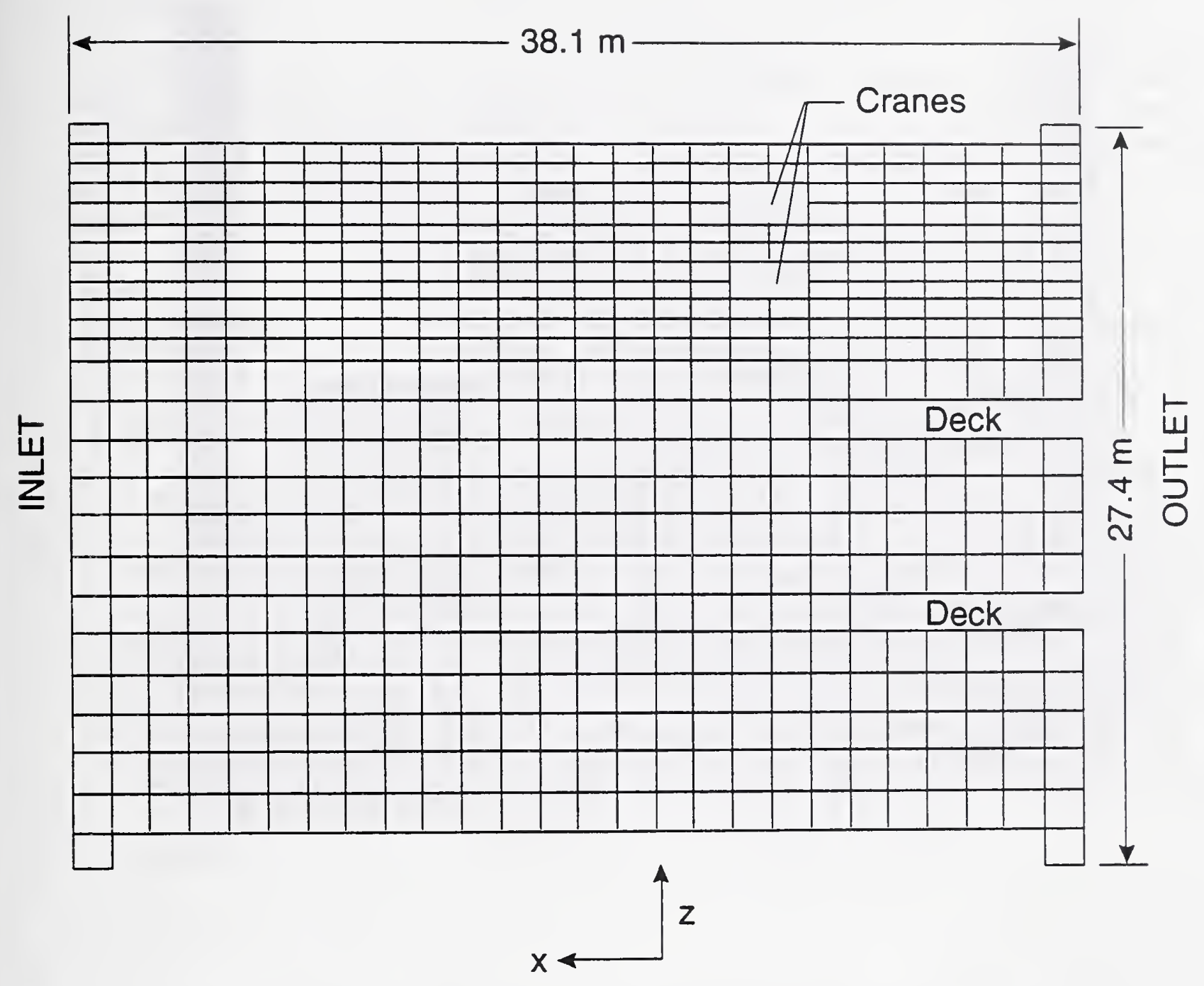

Figure 1. Vertical slice of a typical grid used for the NASA clean room calculation 


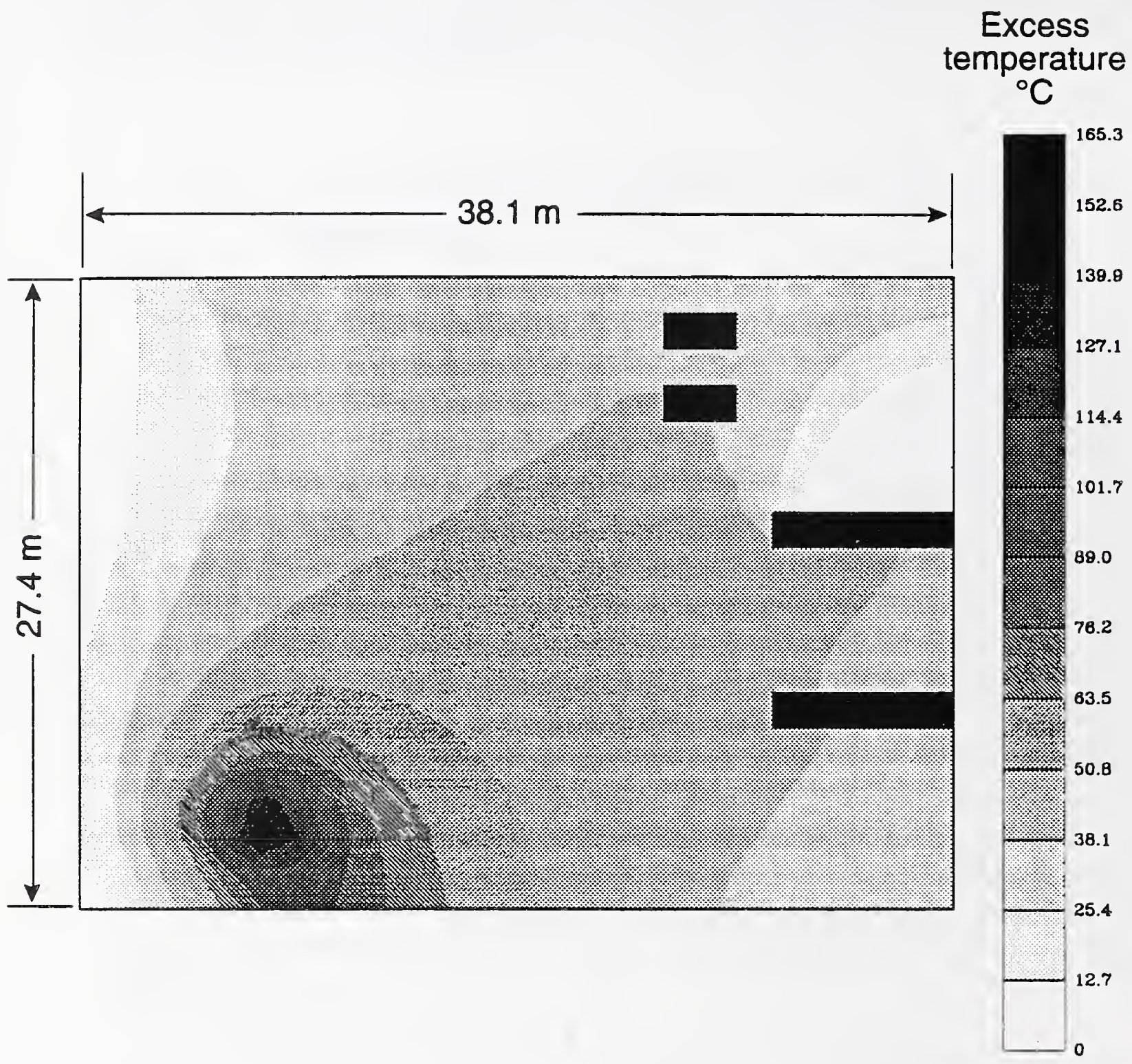

Figure 2. Temperature contours on a vertical plane through the fire for the $32 \mathrm{MW}$ fire calculation 


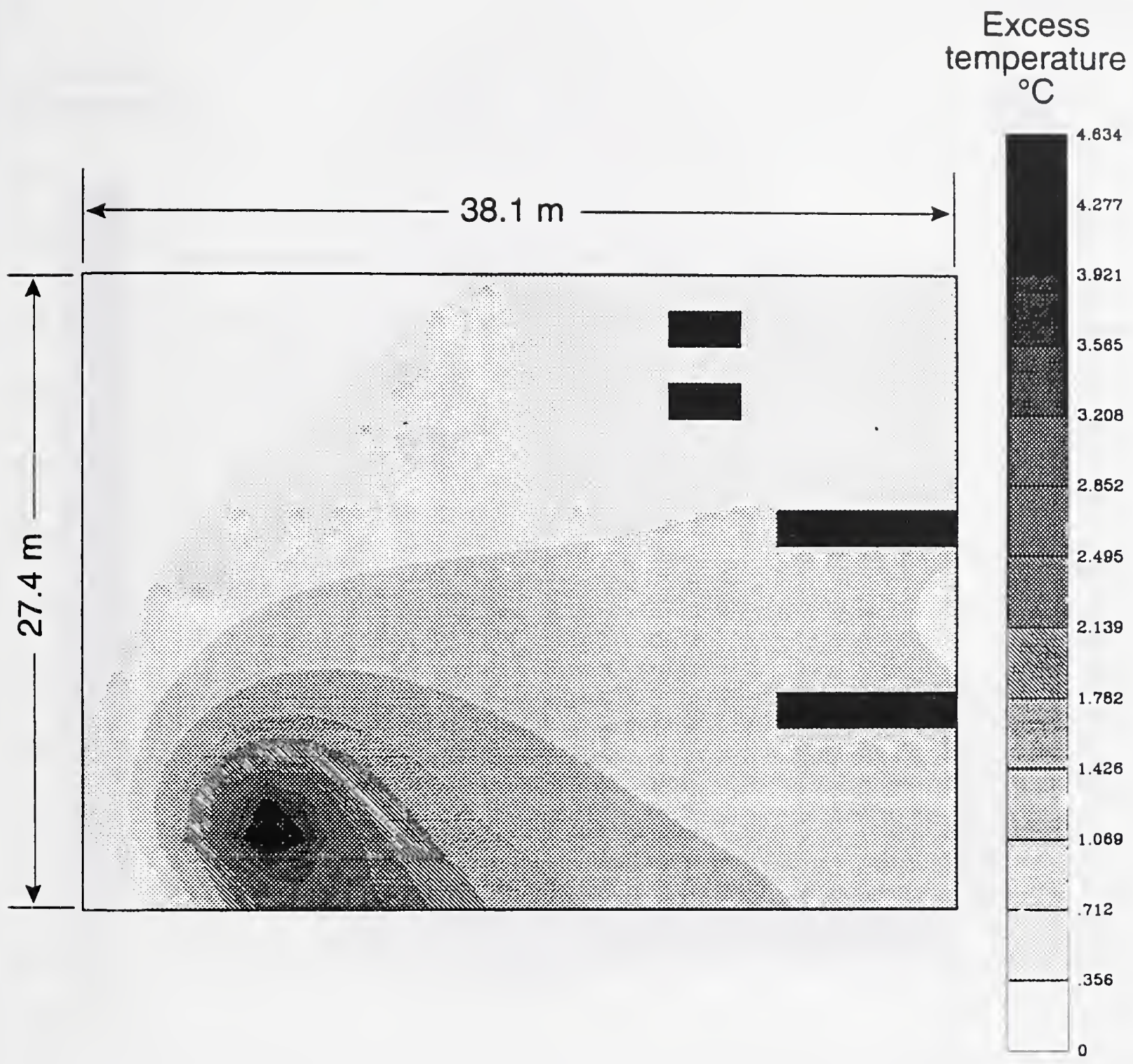

Figure 3. Temperature contours on a vertical plane through the fire for the $400 \mathrm{~kW}$ fire calculation 


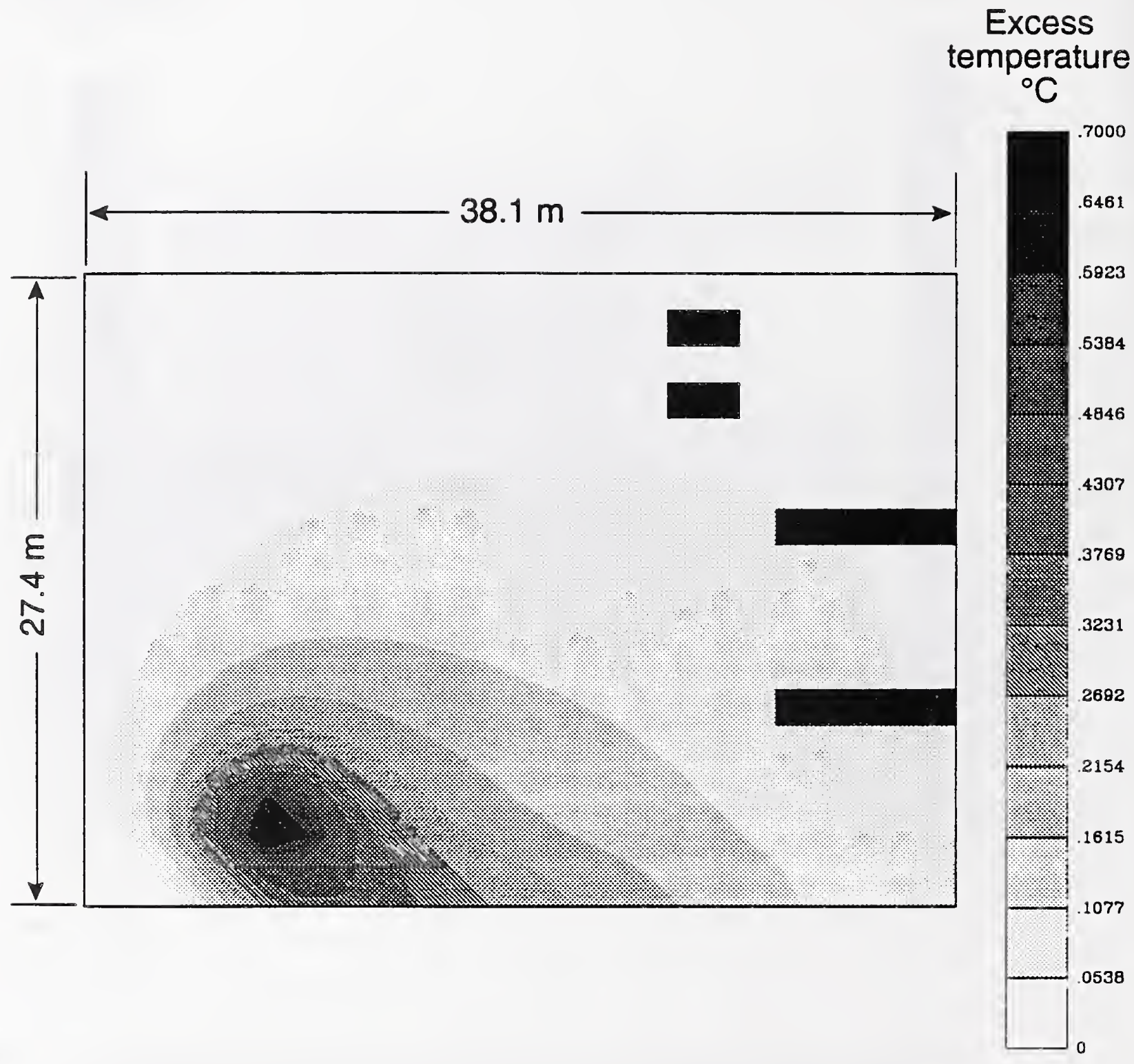

Figure 4. Temperature contours on a vertical plane through the fire for the $40 \mathrm{~kW}$ fire calculation 


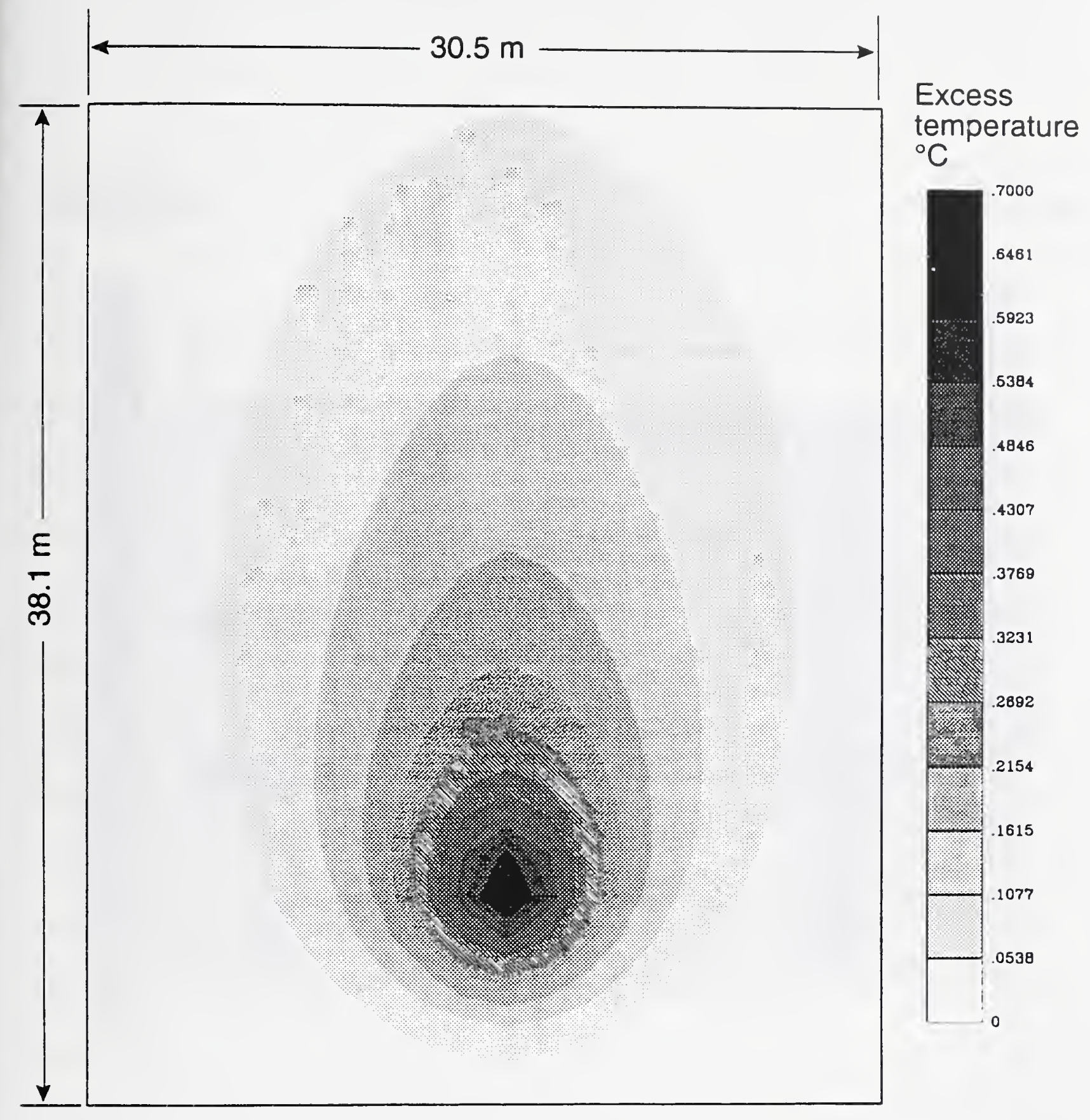

Figure 5. Temperature contours on a horizontal plane centered on the grid directly above the $\mathbf{4 0}$ $\mathrm{kW}$ fire 


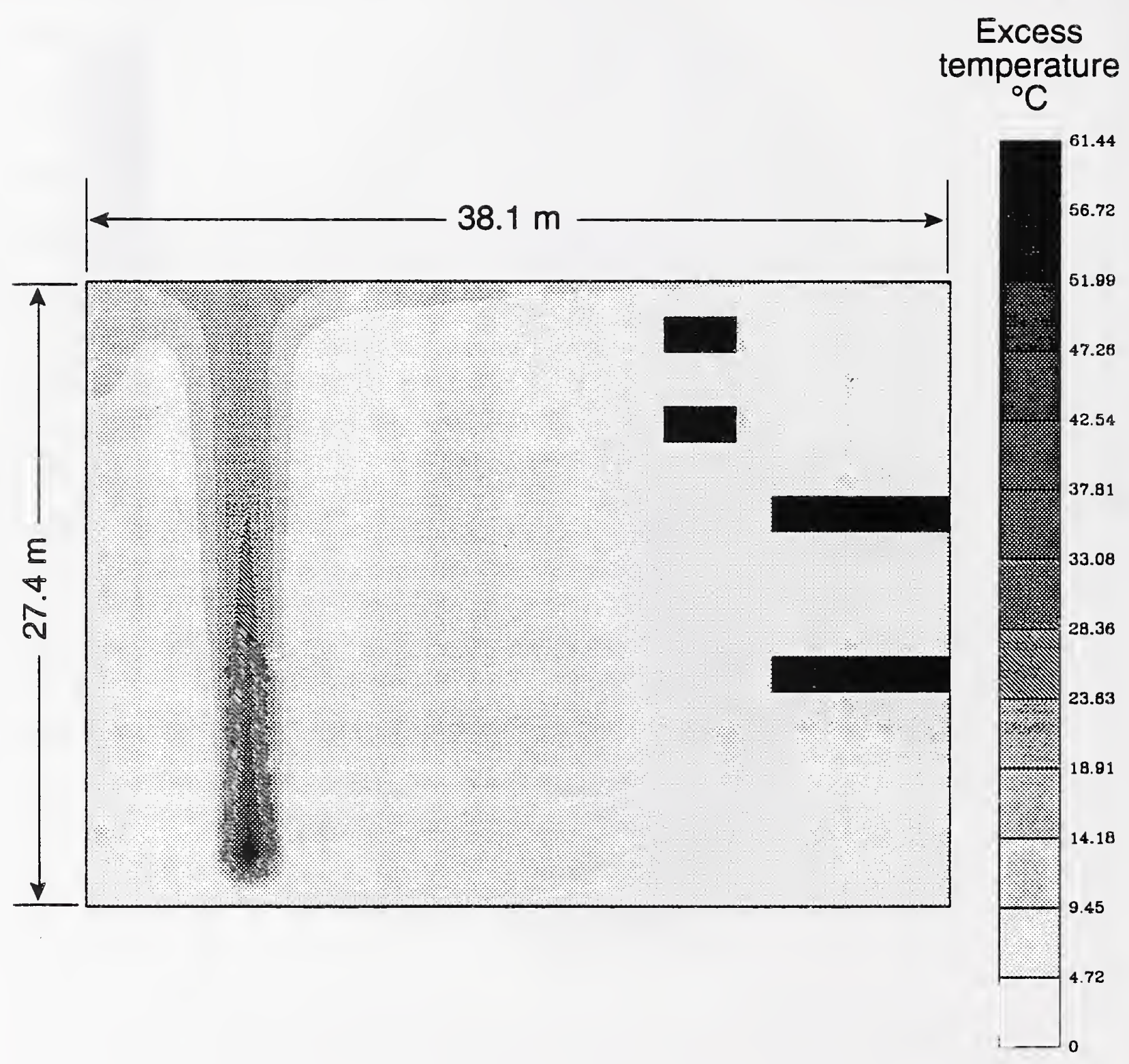

Figure 6. Temperature contours on a vertical plane through the fire at $50 \mathrm{~s}$ after ignition for a $400 \mathrm{~kW}$ fire 


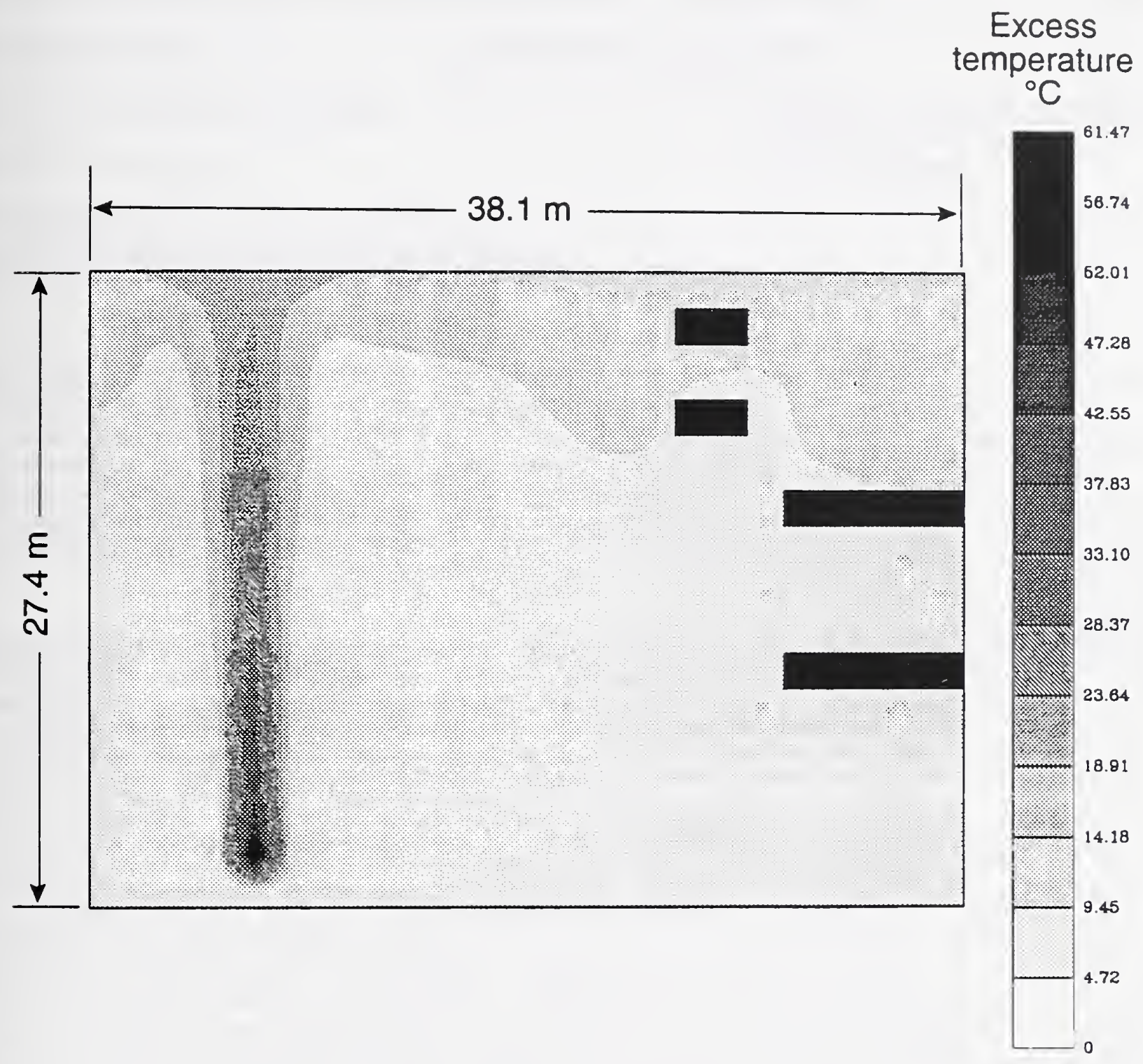

Figure 7. Temperature contours on a vertical plane through the fire at $100 \mathrm{~s}$ after ignition for a $400 \mathrm{~kW}$ fire 



\section{NIST-114}

(REV. 6-93)

ADMAN 4.09
U.S. DEPARTMENT OF COMMERCE NATIONAL INSTITUTE OF STANDARDS AND TECHNOLOGY

MANUSCRIPT REVIEW AND APPROVAL

INSTRUCTIONS: ATTACH ORIGINAL OF THIS FORM TO ONE (1) COPY OF MANUSCRIPT AND SEND TO THE SECRETARY, APPROPRIATE EDITORIAL REVIEW BOARD

TITLE AND SUBTITLE (CITE IN FULL)

THEE USE OF COMPUTER MODELS TO PREDICT TEMPERATURE AND SMOKE MOVEMENT IN HIGH BAY SPACES \begin{tabular}{|l|l|}
\hline CONTRACT OR GRANT NUMBER & TYPE OF REPORT AND/OR PERIOD COVERED \\
\hline
\end{tabular} AUTHOR(S) (LAST NAME, FIRST INITIAL, SECOND INTTIL)

Notarianni, K.A. and Davis, W.D. PERFORMING OROANIZATION (CHECK $(X)$ ONE BOX) $\mathrm{X}$ NIST/GAITHERSBURG NIST/BOULDER JILA/BOULOER LABORATORY AND DIVISION NAMES (FIRST NIST AUTHOR ONLY) Building and Fire Research Laboratory, Fire Science Division (865) SPONSORING ORGANIZATION NAME AND COMPLETE ADDRESS (STREET, CITY, STATE, ZIP)

PROPOSED FOR NIST PUBLICATION JOURNAL OF RESEARCH (NIST JRES) J. PHYS. \& CHEM. REF. DATA (JPCRD) HANDBOOK (NIST HB) SPECIAL PUBLICATION INIST SPY TECHNICAL NOTE (NIST TN) PROPOSED FOR NON-NIST PUBLICATION (CITE FULLY)

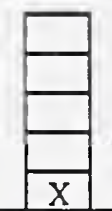

MONOGRAPH (NIST MN)

NATL. STD. REF. DATA SERIES (NIST NSRDS) FEDERAL INF. PROCESS. STDS. (NIST FIPS) LIST OF PUBLICATIONS INIST LPI NIST INTERAGENCYINTERNAL REPORT (NISTIR)

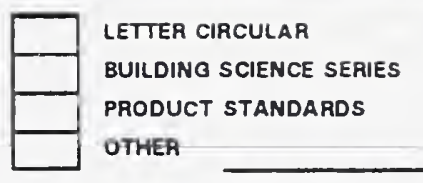

\begin{tabular}{l|l|l|l|l}
\hline $\mathrm{X}$ & U.S. & FOREIGN & PUBLISHING MEDIUM \\
\hline
\end{tabular} LITERATURE SURVEY, CITE IT HERE. SPELL OUT ACRONYMS ON FIRST REFERENCE.) (CONTINUE ON SEPARATE PAGE, IF NECESSARY.) The Building and Fire Research Laboratory (BFRI) was given the opportunity to make measurements during fire calibration tests of the heat detection system in an aircraft hangar with a nominal $30.4 \mathrm{~m}$ (100 ft) ceiling height near Dallas, TX. Fire gas temperatures resulting from an approximately $8250 \mathrm{~kW}$ isopropyl alcohol pool fire were measured above the fire and along the ceiling. The results of the experiments were then compared to predictions from the computer fire models DETACT-QS, FPETOOI and IAVENT. In section A of the analysis conducted, DETACT-QS and FPETOOL significantly underpredicted the gas temperatures. IAVENT at the position below the ceiling corresponding to maximum temperature and velocity provided better agreement with the data. For large spaces, hot gas transport time and an improved fire plume dynamics model should be incorporated into the computer fire model activation routines. A computational fluid dynamics (CFD) model, HARWELL FLow3D, was then used to model the hot gas movement in the space. Reasonable agreement was found between the temperatures predicted from the CFD calculations and the temperatures measured in the aircraft hangar. In section B, an existing NAsA high bay space was modelled using the computational fluid dynamics model. The NAsA space was a clean room, $27.4 \mathrm{~m}$ (90 ft) high with forced horizontal laminar flow. The purpose of this analysis is to determine how the existing fire detection devices would respond to various size fires in the space. The analysis was conducted for $32 \mathrm{MW}, 400 \mathrm{~kW}$, and $40 \mathrm{~kW}$ fires.

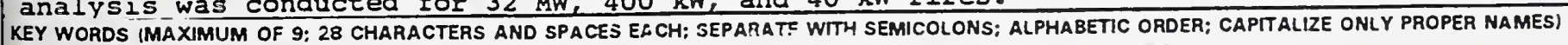

Key words: clean rooms; computer models; computational fluid dynamics; detector response; field modeling; fire detection; fire models; forced air flow; fire plumes; fire tests; high bays; response time; sprinkler response

\section{AVALABILITY}

$X$ UNLIMITED $\square$ FOR OFFICIAL DISTRIBUTION - DO NOT RELEASE TO NTIS ORDER FROM SUPERINTENDENT OF DOCUMENTS, U.S. GPO, WASHINGTON, DC 20402 ORDER FROM NTIS, SPRINGFIELD, VA 22161
NOTE TO AUTHORISI: IF YOU DO NOT WISH THIS MANUSCRIPT ANNOUNCED BEFORE PUBLICATION, PLEASE CHECK HERE. 

i

) 